\title{
An impaired hepatic clock system effects lipid metabolism in rats with nephropathy
}

\author{
PEIPEI CHEN ${ }^{1}$, RUIYU ZHANG ${ }^{1,2}$, LIJUN MOU $^{1,3}$, XUEWANG LI $^{1}$, YAN QIN $^{1}$ and XUEMEI LI ${ }^{1}$ \\ ${ }^{1}$ Department of Nephrology, Peking Union Medical College Hospital, Chinese Academy of Medical Sciences and \\ Peking Union Medical College, Beijing 100730; ${ }^{2}$ Department of Nephrology, Capital Medical University Affiliated \\ with Beijing Anzhen Hospital, Beijing 100029; ${ }^{3}$ Department of Nephrology, The Second Affiliated Hospital, \\ School of Medicine Zhejiang University, Hangzhou, Zhejiang 310009, P.R. China
}

Received April 2, 2018; Accepted August 20, 2018

DOI: $10.3892 /$ ijmm.2018.3833

\begin{abstract}
Hyperlipidemia is a key clinical feature in patients with nephrotic syndrome (NS) that is associated with the incidence of cardiovascular events. Recent studies have suggested that the disorders of triglycerides, gluconeogenesis and liver glucose metabolism are associated with the abnormal transcription of clock genes. However, changes to the circadian rhythm of blood lipids in NS require further exploration, and the effects of NS on the hepatic clock system remain to be elucidated. In the present study, the impaired diurnal rhythm of the hepatic core clock genes (BMAL1, CLOCK, CRY1, CRY2, PERI and $P E R 2)$ significantly induced circadian rhythm abnormalities in liver-specific clock-controlled genes ( $L X R, C Y P 7 A 1$, SREBP-1, $A B C A 1, D E C 1$ and $D E C 2$; all $\mathrm{P}<0.05$ ), which were significantly associated with the abnormal diurnal rhythms of triglyceride, total cholesterol, aspartate aminotransferase and alanine aminotransferase (all $\mathrm{P}<0.05)$ in rats with Adriamycin-induced nephropathy. Furthermore, a protein-protein interaction network was identified. Gene Ontology and Kyoto Encyclopedia of Genes and Genomes pathway analyses based on the human database was conducted to obtain signaling pathway and correlation prediction analyses of overall human clock and clock-controlled gene correlations. Strong correlations of the aforementioned clock genes were detected (avg. local clustering coefficient, 0.849) which suggested significant enrichment in circadian rhythm signaling. The present results indicated that damage to hepatic clock systems may impact blood lipid circadian rhythm disorders in NS, and offer a starting point for understanding the crosstalk between peripheral organs and peripheral clock systems.
\end{abstract}

Correspondence to: Dr Yan Qin, Department of Nephrology, Peking Union Medical College Hospital, Chinese Academy of Medical Sciences and Peking Union Medical College, 1 Shuaifuyuan, Beijing 100730, P.R. China

E-mail: qinyanbeijing@126.com

Key words: nephrotic syndrome, circadian rhythm, clock-controlled genes, blood lipid, bioinformatics

\section{Introduction}

Patients with chronic kidney disease (CKD) exhibit major proatherogenic lipid abnormalities that are associated with their prognosis (1). The severe disorder of lipoprotein metabolism in patients with CKD typically manifests as higher triglyceride (TG) levels and lower levels of high-density lipoprotein cholesterol (HDL-C) (1). Dyslipidemia also increases the incidence of coronary atherosclerosis and cardiovascular events. Notably, improving hyperlipidemia may reduce dialysis morbidity and mortality in patients with end-stage renal disease.

Notably, the mechanisms of dyslipidemia in nephrotic syndrome (NS) are associated with hepatic biology, including liver lipid regulatory enzymes, activity of low-density lipoprotein (LDL) receptors and compensatory synthesis in the liver (2). Liver-associated physiological processes exhibit rhythmicity, and the circadian rhythm activities are regulated by central and hepatic-specific clock systems (3).

Diurnal oscillations are regulated by conserved clock genes in the organism, which act as a hierarchical, collaborative, large-scale 'circadian time' (4). The majority of biological processes, including the maintenance of blood pressure, sleeping and respiratory rhythm, exhibit circadian rhythmicity, and are also regulated by clock genes (5). These genes are expressed in all cell types, including the 'master clock' located in the suprachiasmatic nucleus and the peripheral clock in locations, such as the kidney and liver (4). A previous study indicated that genomic transcription was highly rhythmic, with $\leq 81.7 \%$ of protein-coding genes exhibiting daily rhythms in expression (6). These oscillators dominate the rhythmic expression of downstream clock-regulated genes, accounting for $10-15 \%$ of the genes that regulate the circadian characteristics of the physiological functions of peripheral organs (7).

The cell-autonomous molecular clock in mammals is generated by two interlocking transcription/translation feedback loops (TTFLs) that cooperate to produce robust rhythms of gene expression. The core TTFL is driven by two activators, circadian locomoter output cycles kaput $(C L O C K)$ and brain and muscle ARNT-like protein 1 (BMAL1), and two repressors cryptochrome $(C R Y)$ and period homologue $(P E R)(8)$, which aid the organism to drive circadian rhythms of behavioral activity and hormones (9). Previous studies have 
confirmed that the hepatic clock maintains normal glucose (GLU) levels, fatty acids, fat mobilization and the rhythm of other biochemical reactions in a steady state through the liver $\mathrm{X}$ receptor (LXR), peroxisome proliferator-activated receptor (PPAR) $\gamma$ coactivator and PPAR signaling pathways to regulate TG, cholesterol and fat metabolism under physiological conditions $(3,10)$.

The clock system serves an essential role in homeostasis. Notably, dyslipidemia is considered a homeostasis disorder event in NS. However, the effects of the circadian rhythmicity on blood lipids and the hepatic clock system in this context are unclear. Therefore, the present study was performed to observe the circadian rhythm of lipids and clock genes associated with lipid metabolism in Adriamycin (ADR)-induced nephropathy in rats to explore the potential effects of the clock system on lipid metabolism abnormalities.

\section{Materials and methods}

Experimental animals and treatment protocol. A total of 36 adult male Sprague Dawley rats (8-weeks old; 245-265 g) were purchased from Beijing HFK Bioscience Co., Ltd. (Beijing, China). The animal experimental procedures were approved by the Animal Ethics Committee of Peking Union Medical College Hospital (PUMCH; Beijing, China). Furthermore, all experiments were performed according to international and institutional guidelines for animal care (11), and approved by the PUMC Committee on Animal Care and Use. All rats had access to standard food and tap water ad libitum. Rats were housed at $23 \pm 2^{\circ} \mathrm{C}(12,13)$, under a strict 12-h light/dark regimen whereby zeitgeber time ZT0-ZT12 with the lights on represented the resting phase of the day and ZT12-ZT0 with the lights off represented the active phase of the day. Following 2 weeks of adaptation, rats were randomly divided into two groups: ADR group (ADR-induced nephropathy rats) and control group (saline-treated rats). The NS model was established 14 days from the single intravenous tail injection of $6.5 \mathrm{mg} / \mathrm{kg}$ ADR (dissolved in saline; Pfizer, Inc., New York, NY, USA) according to the protocol by Bertani et al (14). Rats in the control group were injected with an equal volume of saline only. The experimental animals were fasted in a metabolic cage to assess 24-h urine excretion. A 24-h urine excretion value of $>100 \mathrm{mg}$ (15) and foot process effacement of renal tissues detected by electron microscopy (16) indicated the successful establishment of the NS model. After 2 weeks, the rats from the two groups were sampled every $4 \mathrm{~h}$ over $24 \mathrm{~h}$ (3 rats/group at each time point, with a total of 18 normal rats and 18 NS rats). During the sacrificed day, standard food and water was provided ad libitum and treatments were quickly finished to minimize the impact on the timer giver and animal, consistent with other literature methodologies $(12,13)$. The handling of rats during the dark time period was performed under a dim red light, which does not influence endogenous melatonin production (17).

Blood samples and liver tissue. Rats from each group were sacrificed at ZT 2:00, 6:00, 10:00, 14:00, 18:00 and 22:00 h. The liver tissues were immediately frozen in liquid nitrogen and stored in RNAlater (cat. no. AM7020; Ambion; Thermo Fisher Scientific, Inc., Waltham, MA, USA) at $-80^{\circ} \mathrm{C}$. Blood samples were centrifuged at $6,391 \times \mathrm{g}$ for $10 \mathrm{~min}$ at $4^{\circ} \mathrm{C}$. Samples were sent to the Department of Laboratory Medicine, PUMCH (Beijing, China). The following measurements were performed with a Hitachi Modular P800 analyzer (Hitachi, Ltd., Tokyo, Japan): Serum total cholesterol (TC) (CHOD-PAP method; Roche Diagnostics GmbH, Mannheim, Germany) (18), serum TGs (GP0-PAP method; Roche Diagnostics GmbH), and HDL-C (Roche HDL-C Plus 2nd generation kit; Roche Diagnostics GmbH). LDL-C was calculated using the Friedewald formula (19). Albumin was measured using the bromo-potassium phenol green method (20) and serum creatinine was measured using a sarcosine oxidase method (21). Aspartate aminotransferase (AST) and alanine aminotransferase (ALT) activity was assessed with an automatic biochemical analyzer. Furthermore, GLU levels were measured using the hexokinase method (22).

Transmission electron microscopy analyses. Fresh rat renal tissues were removed in sections of $\sim 2.0 \mathrm{~mm}^{3}$ and fixed with $2.5 \%$ glutaraldehyde in $0.1 \mathrm{M}$ Sorenson's phosphate buffer $(\mathrm{pH}=7.41)$ for $2 \mathrm{~h}$ at $4^{\circ} \mathrm{C}$. Following this, the samples were washed three times with $0.1 \mathrm{M}$ Sorenson's phosphate buffer. The tissues were subsequently post-fixed for $1-1.5 \mathrm{~h}$ in $1 \%$ $\mathrm{OsO}_{4}$ in $0.1 \mathrm{M}$ Sorenson's phosphate buffer, washed with distilled water, then stained en bloc with $3 \%$ uranyl acetate for $30 \mathrm{~min}$ at $25^{\circ} \mathrm{C}$. Dehydration was performed using a $50-95 \%$ graded ethanol series, followed by two changes in propylene oxide. Sections of 70-80 nm were cut, and collected on a 200 copper/rhodium grid stained with uranyl acetate and lead citrate. Following this, samples were observed under a transmission electron microscope (magnification, $x 5,000$ ).

Reverse transcription-quantitative polymerase chain reaction (RT-qPCR) analysis. Total RNA was extracted from frozen heart tissues using RNAiso Plus reagents (cat. no. 9109; Takara Bio, Inc., Otsu, Japan) according to the manufacturer's protocol. RNA was reverse transcribed using the PrimeScript ${ }^{\circledR}$ RT Master Perfect Real-time kit (cat. no. DRR036A; Takara Bio, Inc.). The resulting cDNA was amplified using a SYBR-Green PCR kit (cat. no. DRR082A; Takara Bio, Inc.) and detected with a 7500 Fast Real-time PCR system (Applied Biosystems; Thermo Fisher Scientific, Inc.). All experiments were performed at least three times according to the manufacturer's protocol. The conditions for the two-step amplification PCR reaction were pre-denaturation $\left(95^{\circ} \mathrm{C}, 30 \mathrm{sec}, 1 \mathrm{cycle}\right)$ and PCR amplification $\left(95^{\circ} \mathrm{C}, 5 \mathrm{sec}\right.$ and $60^{\circ} \mathrm{C}, 30 \mathrm{sec}, 40$ cycles $)$. Gene expression was calculated relative to the housekeeping gene GAPDH using the $2^{-\Delta \Delta \mathrm{Cq}}$ method (23). The primers used for PCR are presented in Table I.

Protein-protein interaction (PPI) network and functional enrichment of protein-coding genes. Due to the difficulties of obtaining human tissues to explore the rhythmic characteristics of clock gene expression levels every $4 \mathrm{~h}$, correlation analyses of the expression levels of human proteins were performed using the STRING database (http://www.string-db.org/) (24) as a complementary platform to assessed the association between core clock and clock-controlled genes in patients with renal disease. Furthermore, the DAVID Bioinformatics Tool (25) was used to identify functional enrichment of target 
Table I. Primers for reverse transcription-quantitative polymerase chain reaction.

\begin{tabular}{|c|c|c|}
\hline Gene & Forward (5'-3') & Reverse (5'-3') \\
\hline GAPDH & GACAACTTTGGCATCGTGGA & ATGCAGGGATGATGTTCTGG \\
\hline CLOCK & CATCGGCAGCAAGAAGAACT & CAAGATTCAGTCCAGGGTTTG \\
\hline BMAL1 & CAACCCATACACAGAAGCAAAC & ACAGATTCGGAGACAAAGAGGA \\
\hline PER1 & GAGGAGCCAGAGAGGAAAGAGT & TTGGTTGTGTTAGGAATGTTGC \\
\hline PER2 & CTGGAAAGAACAGGAAACTGAA & GGGAACACAGGTAGTGGGTAAG \\
\hline CRYI & ATCTAGCCCGACATGCAGTT & TCGGCGTCAAGCAGTAATTC \\
\hline CRY2 & ATTGAGCGGATGAAGCAGAT & TCTACACAGGAAGGGACAGATG \\
\hline$L X R$ & CCTGATGTTTCTCCTGACTC & TGACTCCAACCCTATCCTTA \\
\hline$D E C 1$ & CCACCAAAAAGAGCCGAAT & ATAGAAGGGCAGGCAAAAGG \\
\hline$D E C 2$ & GAAGCGAGACGACACCAAG & TTTCAGATGTTCAGGCAGTAAGTC \\
\hline$S R E B P-1$ & GGAGCCATGGATTGCACATT & GGCCCGGGAAGTCACTGT \\
\hline$A B C A 1$ & CTTGCTTCCGTTATCCAACTCCAG & GCTGTAATGTTCTCAGGACCTTGTG \\
\hline CYP7A1 & CCAAGTCAAGTGTCCСССТCTA & GACTCTCAGCCGCCAAGTG \\
\hline
\end{tabular}

$C L O C K$, circadian locomoter output cycles kaput; BMAL1, brain and muscle ARNT-like protein 1; CRY, cryptochrome; PER, period homologue; $L X R$, liver $\mathrm{X}$ receptor; $C Y P 7 A 1$, cholesterol $7 \alpha$-hydroxylase; $S R E B P-1$, sterol regulatory element binding protein-1c; $A B C A 1, \mathrm{ATP}$ binding cassette transporter A1; $D E C$, differentiated embryo chondrocyte.

protein-coding genes. Notably, this tool may be used to identify Gene Ontology (GO) biological processes associated with protein-coding genes. Furthermore, KEGG pathway enrichment analysis was performed using KOBAS 3.0 (http://kobas. cbi.pku.edu.cn/). Cytoscape (www.cytoscape.org/) (26) was also used to visualize the above biological process organization and GOplot (http://wencke.github.io/) (27) was used to illustrate the functional analysis data.

Statistical analysis. The results are presented as the mean \pm standard deviation, and the data were analyzed using unpaired t-tests with SPSS 20.0 software (IBM Corp., Armonk, $\mathrm{NY}$, USA) for comparisons between groups. $\mathrm{P}<0.05$ was considered to indicate a statistically significant difference. Gene expression data and blood parameters were analyzed to assess the circadian rhythmicity of data using a Fourier transform method and Chronos-Fit software (http://chronos-fit.software. informer.com/). Following the Chronos-Fit software formula: $\mathrm{F}(\mathrm{t})=$ mesor $\sum\left(\right.$ amplitude $_{\mathrm{i}} \times \cos \left(\mathrm{t}-\right.$ acrophase $\left.\left._{\mathrm{i}}\right) \times 2 \pi / \mathrm{pi}\right)$. The parameters included the mean, midline estimating statistic of rhythm (mesor), amplitude of the sine wave (amplitude) and the acrophase or time of maximum of the sine wave (acrophase). The chart indicated the curve fitted to the circadian analysis of all clock genes. Significance $(\mathrm{P}<0.05)$ was evaluated using the F-test as described previously $(28,29)$.

\section{Results}

Rats with nephropathy exhibit hyperglycemia and disordered rhythms in serum TC, TG, AST and ALT levels. The ADR-induced nephropathy model is a classical nephropathy animal model $(16,30)$. In the present study, 2 weeks following ADR injection, the ADR group presented with minimal change in disease according to the electron microscopy results (Fig. 1). The levels of blood TC, TG, HDL-C, LDL cholesterol (LDL-C) and GLU over $24 \mathrm{~h}$ were significantly increased in the ADR group compared with the control group (all $\mathrm{P}<0.05$, Table II). AST and ALT activity was also significantly increased in the ADR group compared with the control group
Table II. Laboratory parameters in the two groups.

\begin{tabular}{lccc}
\hline Measure & $\begin{array}{c}\text { SD rats } \\
(\mathrm{n}=18)\end{array}$ & $\begin{array}{c}\text { ADR rats } \\
(\mathrm{n}=18)\end{array}$ & P-value \\
\hline ALB $(\mathrm{g} / \mathrm{l})$ & $29.78 \pm 2.13$ & $22.14 \pm 2.75^{\mathrm{a}}$ & $<0.05$ \\
$\mathrm{SCr}(\mu \mathrm{mol} / \mathrm{l})$ & $34.05 \pm 13.94$ & $39.06 \pm 7.59$ & 0.231 \\
BUN $(\mathrm{mmol} / \mathrm{l})$ & $7.01 \pm 1.34$ & $7.00 \pm 1.50$ & 0.968 \\
TC $(\mathrm{mmol} / \mathrm{l})$ & $1.80 \pm 0.29$ & $4.45 \pm 1.47^{\mathrm{a}}$ & $<0.05$ \\
TG $(\mathrm{mmol} / \mathrm{l})$ & $0.71 \pm 0.56$ & $3.97 \pm 2.87^{\mathrm{a}}$ & $<0.05$ \\
HDL-C $(\mathrm{mmol} / \mathrm{l})$ & $0.59 \pm 0.09$ & $1.27 \pm 0.38^{\mathrm{a}}$ & $<0.05$ \\
LDL-C $(\mathrm{mmol} / \mathrm{l})$ & $0.25 \pm 0.05$ & $0.68 \pm 0.23^{\mathrm{a}}$ & $<0.05$ \\
GLU $(\mathrm{mg} / \mathrm{dl})$ & $176.64 \pm 21.55$ & $336.89 \pm 102.65^{\mathrm{a}}$ & $<0.05$ \\
AST $(\mathrm{U} / \mathrm{l})$ & $88.30 \pm 16.73$ & $120.51 \pm 22.85^{\mathrm{a}}$ & $<0.05$ \\
ALT $(\mathrm{U} / \mathrm{l})$ & $51.73 \pm 10.66$ & $70.59 \pm 15.30^{\mathrm{a}}$ & $<0.05$ \\
$24 \mathrm{~h} \mathrm{UP}(\mathrm{mg} /$ day $)$ & $21.70 \pm 7.53$ & $178.30 \pm 68.53^{\mathrm{a}}$ & $<0.05$ \\
\hline
\end{tabular}

${ }^{\mathrm{a}} \mathrm{P}<0.05$ (between-group comparison). Values are expressed as the mean \pm standard deviation. ALB, albumin; $\mathrm{SCr}$, serum creatinine; $\mathrm{BUN}$, blood urea nitrogen; TC, total cholesterol; TG, triglyceride; HDL-C, high-density lipoprotein cholesterol; LDL-C, low-density lipoprotein cholesterol; GLU, glucose; AST, Aspartate aminotransferase; ALT, Alanine aminotransferase; 24 h UP, urine protein; SD, Sprague-Dawley control rats; ADR, Adriamycin-induced nephropathy.

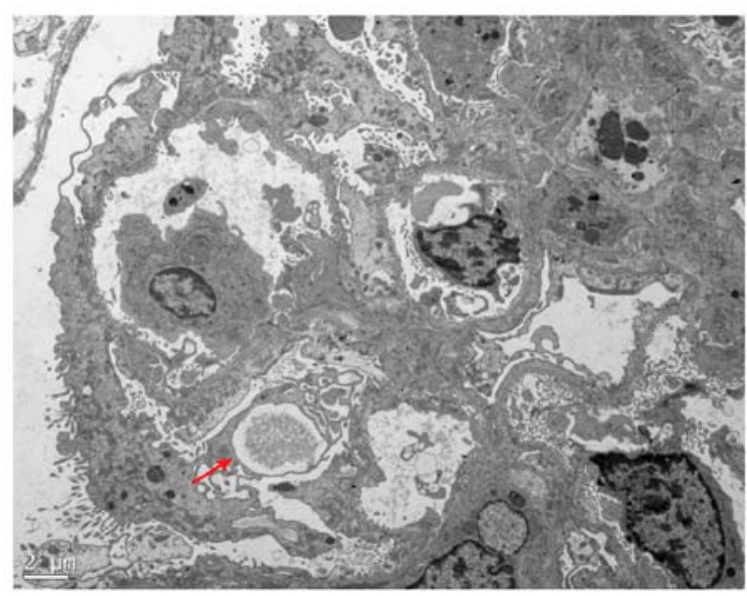

Figure 1. Electron microscopic observation of extensive foot process fusion in renal tissue of Adriamycin-induced nephropathy rats (red arrow). 

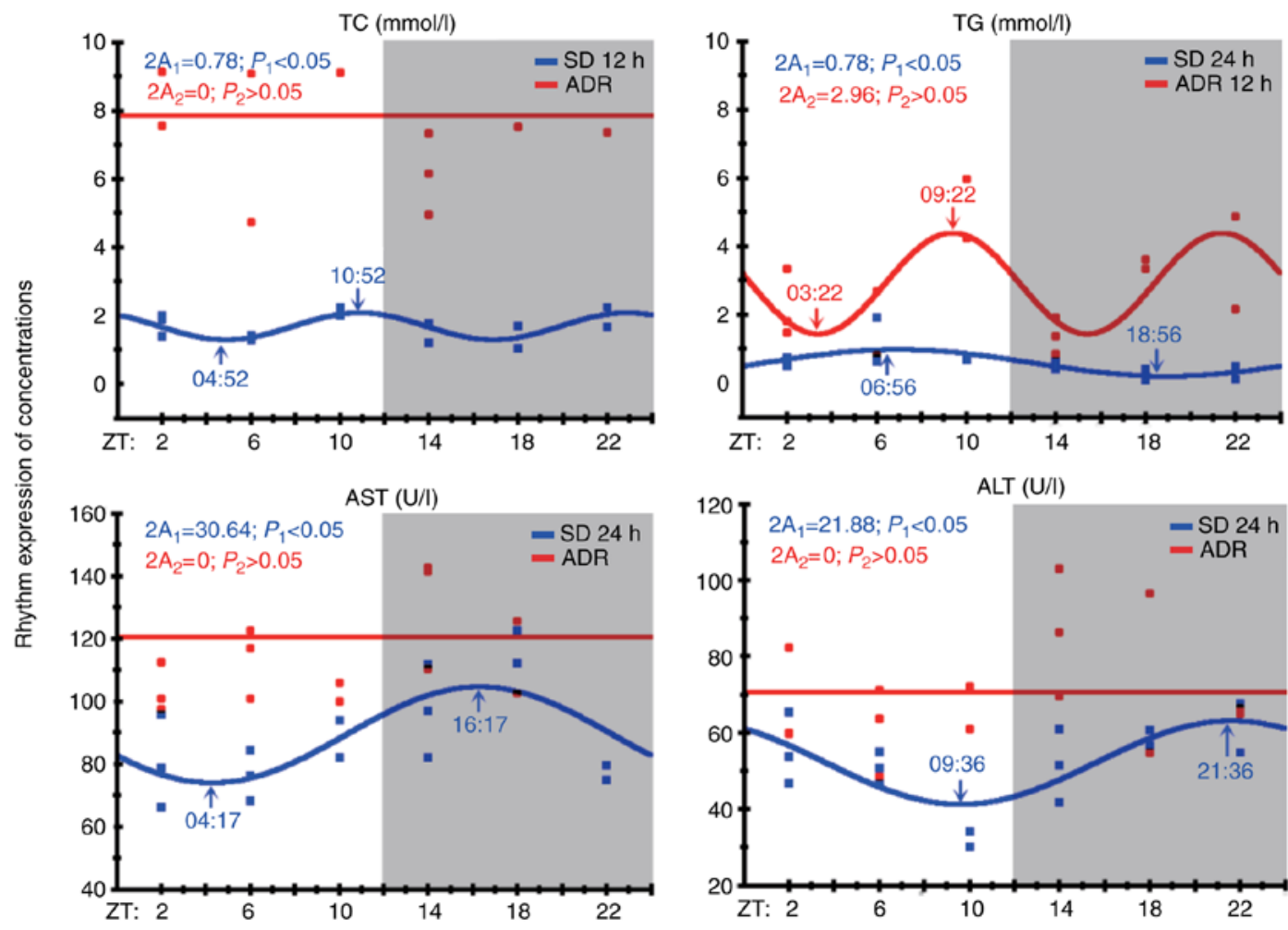

Figure 2. TC, TG, AST and ALT levels are associated with a circadian pattern. Arrows in each figure indicate the ZT was associated with the peak value and off-peak value of the fitted curve (acrophase). The chart shows the fitted curve generated by circadian analysis of all clock genes; this curve was checked for significance using the F-test $(\mathrm{P}<0.05)$. 2A1 is the double amplitude of the control group, and 2A2 is the double amplitude of the ADR group. Gray area, dark period ( $\mathrm{ZT}=12: 00-24: 00)$; white area, light period ( $\mathrm{ZT}=00: 00-12: 00)$. The blue and red dots indicate the measured TC, TG, AST and ALT levels in the control and ADR groups during the light and dark periods, respectively. Partial Fourier analysis, n=36, three rats/group every $4 \mathrm{~h}$ in $24 \mathrm{~h}$. ADR, Adriamycin-induced nephropathy; TC, total cholesterol; TG, triglyceride; AST, aspartate aminotransferase; ALT, alanine aminotransferase; ZT, Zeitgeber time.

( $\mathrm{P}<0.05$, Table II). In the control group, the serum levels of TC, TG, AST and ALT were significantly cycled every $12,24,24$ or $24 \mathrm{~h}$, respectively (all $\mathrm{P}<0.05$ ), and the double amplitudes $(2 \mathrm{~A})$ of the TC and TG levels were similar $(2 \mathrm{~A}=0.78)$. However, in the ADR group, the rhythm of the TG levels changed from the baseline of 24 to $12 \mathrm{~h}$, and no oscillations were observed with regards to TC, AST and ALT levels (all P>0.05; Fig. 2). The HDL-C, LDL-C and GLU levels in the two groups did not indicate a circadian rhythm (F-test, $\mathrm{P}>0.05$; data not shown).

Hepatic core clock and clock-controlled genes that regulate $T G$, cholesterol and fat metabolism are associated with disordered rhythms in NS rats. The circadian rhythm of six hepatic core clock genes and six clock-controlled genes associated with metabolism were evaluated. The data revealed the $C R Y 1$ and PER2 genes exhibited 24-h rhythmicity, and their peak times advanced by 0.5 and $2.5 \mathrm{~h}$ compared with those in the control group; however, the rhythm of PERl mRNA expression was wholly absent in the ADR group $(\mathrm{P}<0.05)$. Other core clock genes, including CLOCK and CRY2, exhibited a change in periodicity from 24 to $12 \mathrm{~h}$, and their peak times significantly shifted to the rest period (daytime; $\mathrm{P}<0.05$ ). Furthermore, the rhythm of BMAL1 mRNA expression changed from $24 \mathrm{~h}$ to a period of $4.8+6 \mathrm{~h}(\mathrm{P}<0.05$; Fig. 3A).

The liver-specific clock-controlled genes, including $L X R$, cholesterol $7 \alpha$-hydroxylase $(C Y P 7 A 1)$, sterol regulatory element binding protein-1c (SREBP-1), ATP binding cassette transporter $\mathrm{A} 1(A B C A 1)$ and the basic helix-loop-helix transcription factors, differentiated embryo chondrocyte1 (DEC1) and $D E C 2$. The rhythms of the mRNA expression levels of $D E C 1, D E C 2$, SREBP-1 and $A B C A 1$ were completely absent in the livers in the ADR group $(\mathrm{P}<0.05)$. Although $L X R$ and CYP7A1 maintained circadian rhythm characteristics, the time periods in the ADR group compared with the control rats changed for $L X R$ (from $24 \mathrm{~h}$ to $12+24 \mathrm{~h}$ ) and CYP7Al (from 4.8 to $24 \mathrm{~h}$; all $\mathrm{P}<0.05$; Fig. $3 \mathrm{~B}$ ).

Functional annotation and PPI network construction. Highly associated genes in a given genetic module serve important roles in biological processes (31). Therefore, the six aforementioned hepatic core clock genes and six clock-controlled genes that were highly associated with the hepatic circadian rhythms of blood lipid metabolism were selected, and PPI networks were constructed using STRING (32). These genes in the PPI network were identified to have stronger interactions among themselves (average local clustering coefficient, 0.849; Fig. 4 and Table III). Notably, the PPI network of STRING v10 makes use of all microarray gene expression experiments deposited in the NCBI Gene Expression Omnibus to provide co-expression analysis, which is a reliable indicator of functional associations (33).

To gain insight into the functional characteristics of the identified blood lipid metabolism-associated protein-coding core clock and clock-controlled genes, GO and KEGG pathway enrichment analyses were performed using DAVID (34). Molecular information was added to GO terms 

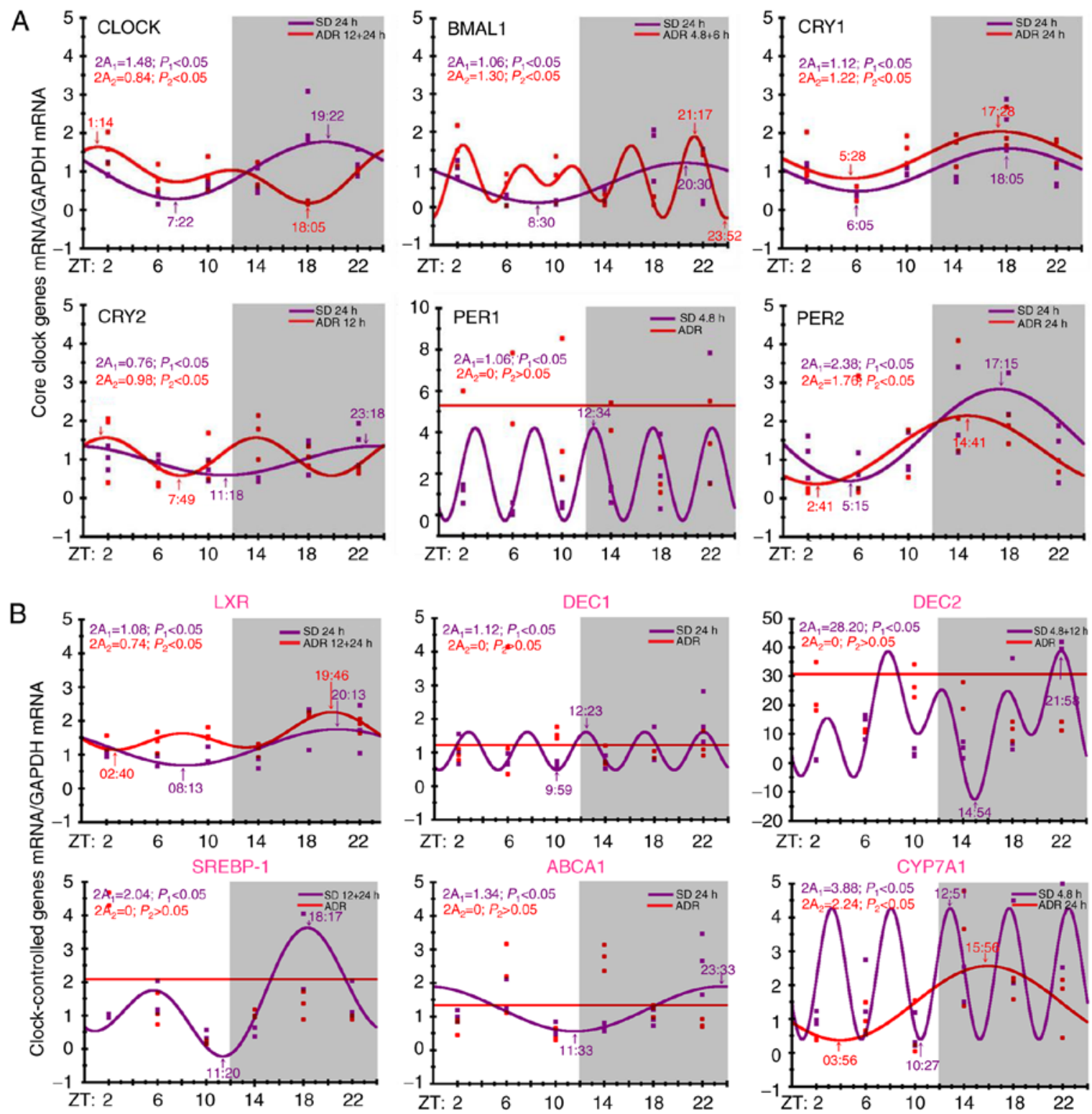

Figure 3. Circadian pattern expressions. (A) Circadian pattern expression of hepatic core clock genes: $C L O C K$ and $B M A L$; and two repressors $C R Y$ and $P E R$. (B) Circadian pattern expression of clock-controlled genes: LXR, CYP7A1, SREBP-1 and ABCA1; and the basic helix-loop-helix transcription factors, DEC1 and $D E C 2$. The purple and red dots indicate the measured gene expression values in the control and ADR groups, respectively. ADR, Adriamycin-induced nephropathy; $C L O C K$, circadian locomoter output cycles kaput; $B M A L 1$, brain and muscle ARNT-like protein 1; $C R Y$, cryptochrome; $P E R$, period homologue; $L X R$, liver X receptor; $C Y P 7 A 1$, cholesterol $7 \alpha$-hydroxylase; $S R E B P$-1, sterol regulatory element binding protein-1c; ABCA1, ATP binding cassette transporter A1; DEC, differentiated embryo chondrocyte.

of potential associated genes of circadian rhythms of blood lipid metabolism (Fig. 5). In terms of biological processes, the GO analysis indicated that the clock system protein-coding genes were significantly (all $\mathrm{P}<0.05$ ) enriched in the circadian regulation of gene expression (GO:0006351), the negative regulation of the glucocorticoid receptor signaling pathway (GO:2000323) and DNA-templated transcription (GO:0045892). In terms of molecular function (MF), the genes were enriched in E-box binding (GO:0070888), transcription factor activity and transcription factor binding (GO:0000989), and transcription regulatory region sequence-specific DNA binding (GO:0000976). Additionally, GO cellular component (CC) analysis revealed that the genes were significantly enriched in the nucleus, chromatoid body and intracellular membrane-bound organelles.
Additionally, a graphic representation of the complicated association between clock genes and the respective GO terms, including a 'concept-and-gene network', was constructed using the GeneAnswers R package (35). To add quantitative molecular data to the GO terms of interest, the GOCircle plot, GOChord and GOCluster plot functions of the GOplot R package were added (27) (Figs. 6 and 7). These functions permit the incorporation of data derived from expression level measurements with those obtained from functional annotation enrichment analysis (Table IV).

According to the interactions between the clock genes and the intersecting pathway genes, a clock gene network was constructed that illustrated the network pathway and the key regulatory functions of the identified clock genes. Using KEGG pathway enrichment analysis of Cytoscape and the 


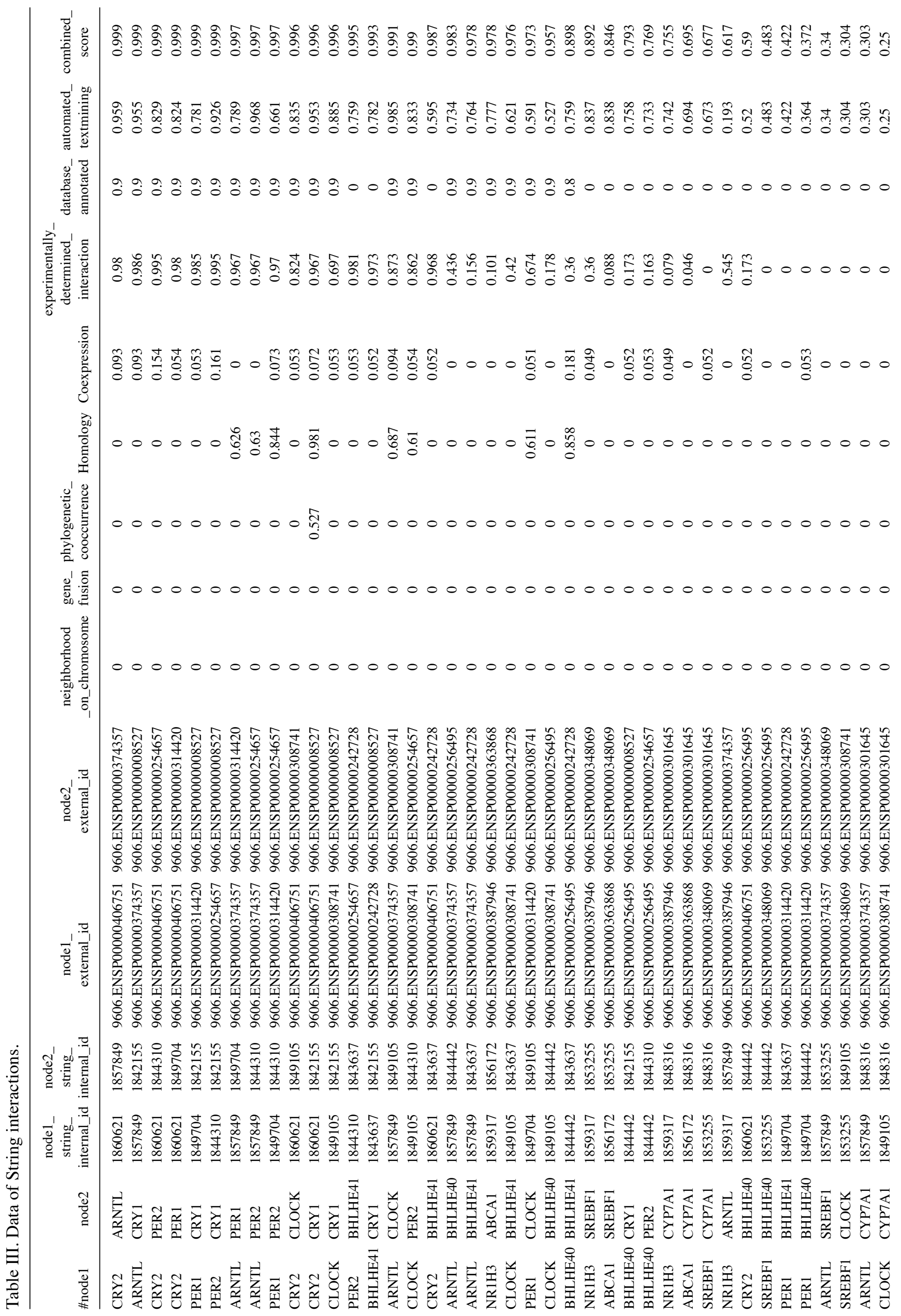




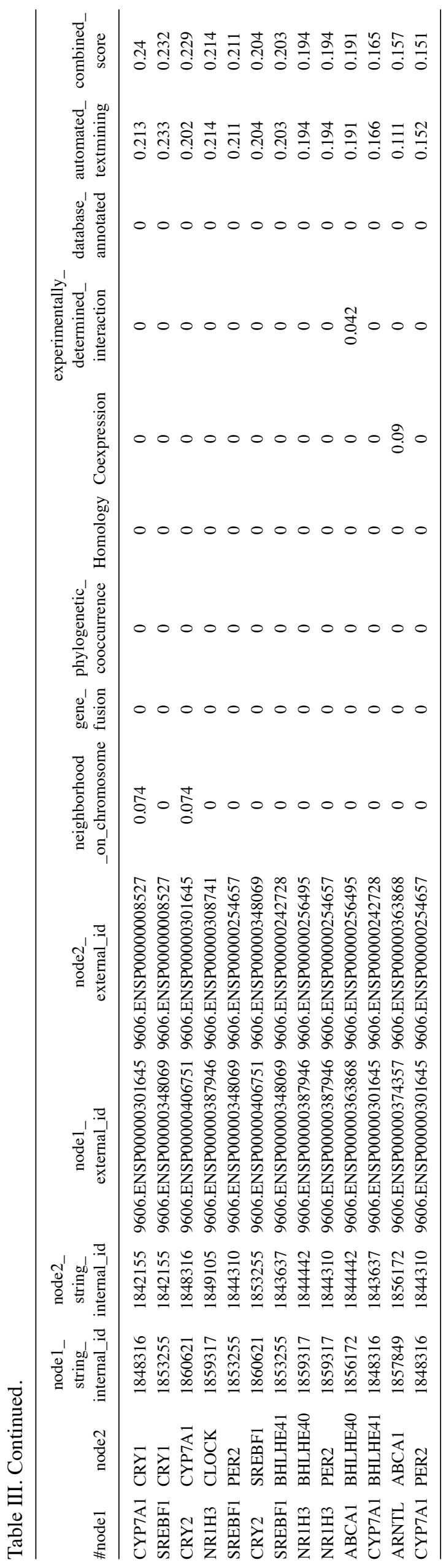

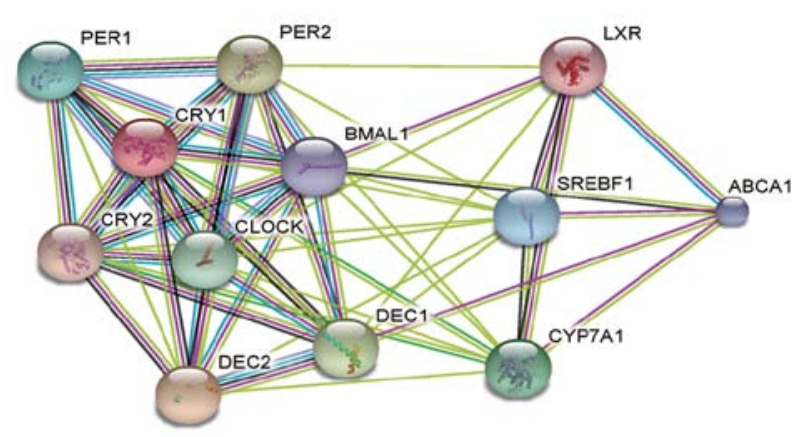

Figure 4. Protein-protein interaction network constructed with the 12 clock and clock-controlled genes. Genes were enriched in the differential pathways identified in the Homo sapiens genome (avg. local clustering coefficient, 0.849). The colored nodes/lines represent different proteins/protein-protein interactions.

KOBAS network, the rhythmically expressed protein-coding genes were determined to be significantly enriched in circadian rhythm (hsa04710), PPAR signaling pathways (hsa03320), circadian entrainment (hsa04713), fat digestion and absorption (hsa04975) and ABC transporters (hsa02010); Fig. 8 and Table V).

\section{Discussion}

The majority of studies suggest that the lipid metabolism involved in kidney disease primarily affects local tissue lipid deposition and local tissue energy barriers (36). However, serum cholesterol levels of patients with CKD are determined by endogenous synthesis and intestinal absorption of exogenous cholesterol (37). Although numerous tissues (endocrine organs, the immune system, the endothelium) contribute to the plasma protein pool, the bulk of plasma proteins is secreted by the liver and are those lost to the highest extent in the NS (38). Additionally, three-quarters of the total cholesterol is synthesized in the liver (39), thus, it was hypothesized that renal injury affects peripheral blood lipid levels through the liver. Therefore, the present study focused on the hepatic clock system that affects circulating lipids.

Clinicians usually overlook the circadian rhythm of blood lipids. Few primary research studies have explored the circadian rhythm of blood lipids (40-42). However, previous studies have suggested that the deletion or knockdown of mouse core clock genes results in several circadian rhythm abnormalities concerning TGs, gluconeogenesis and liver GLU metabolism $(40,43)$. It is well acknowledged that hyperlipidemia occurs in patients with NS and improves immediately with the remission of NS. It is an excellent model of kidney disease to explore the circadian rhythm of blood lipids, and the underlying crosstalk between kidney and liver.

In the present study, nephropathy induced by ADR in rats presented with the typical characteristics of normal renal function, hypoalbuminemia and hyperlipidemia. Electron microscopy indicated partial podocyte fusion, which is a major cause of idiopathic NS. Multiple and large doses (total $>10 \mathrm{mg} / \mathrm{kg}$ ) of Adriamycin are associated with the development of rat hepatic lesions (44), whereby Adriamycin causes significant abnormalities in liver function parameters. In previous studies, the single dose of Adriamycin generally used 


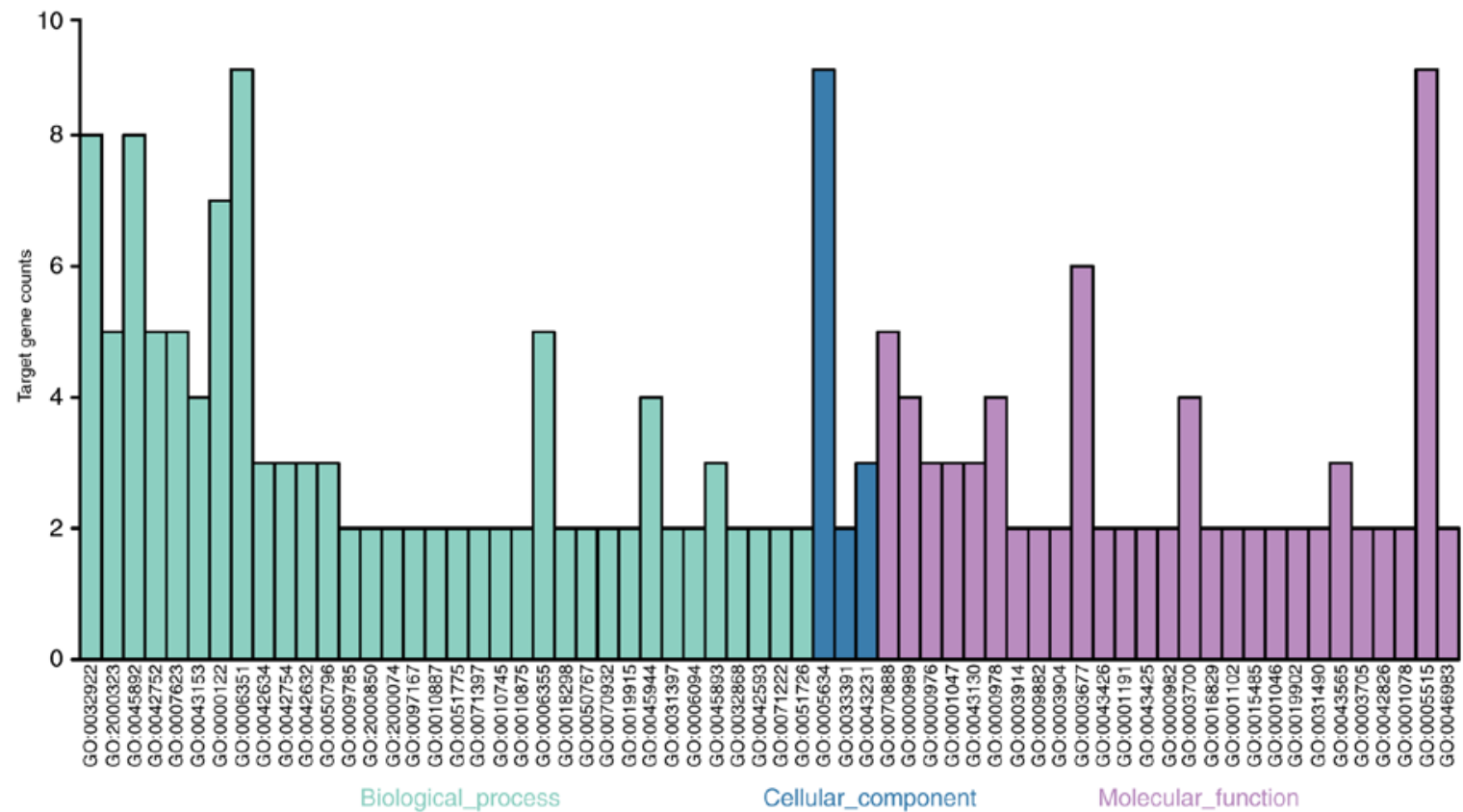

Figure 5. Target gene counts of GO biological processes. The GO analysis results demonstrated that the clock system protein-coding genes were significantly enriched in the circadian regulation of gene expression (GO:0006351), negative regulation of glucocorticoid receptor signaling pathway (GO:2000323) and DNA-templated (GO:0045892) under BPs (light blue bar). Under MF (purple), the genes were enriched in E-box binding (GO:0070888), transcription factor activity, transcription factor binding (GO:0000989) and transcription regulatory region sequence-specific DNA binding (GO:0000976). Additionally, GO CC (dark blue bar) analysis revealed genes significantly were enriched in the nucleus, chromatoid body and the intracellular membrane-bounded organelle. GO, Gene Ontology; BP, biological process; CC, cellular component; MF, molecular function.

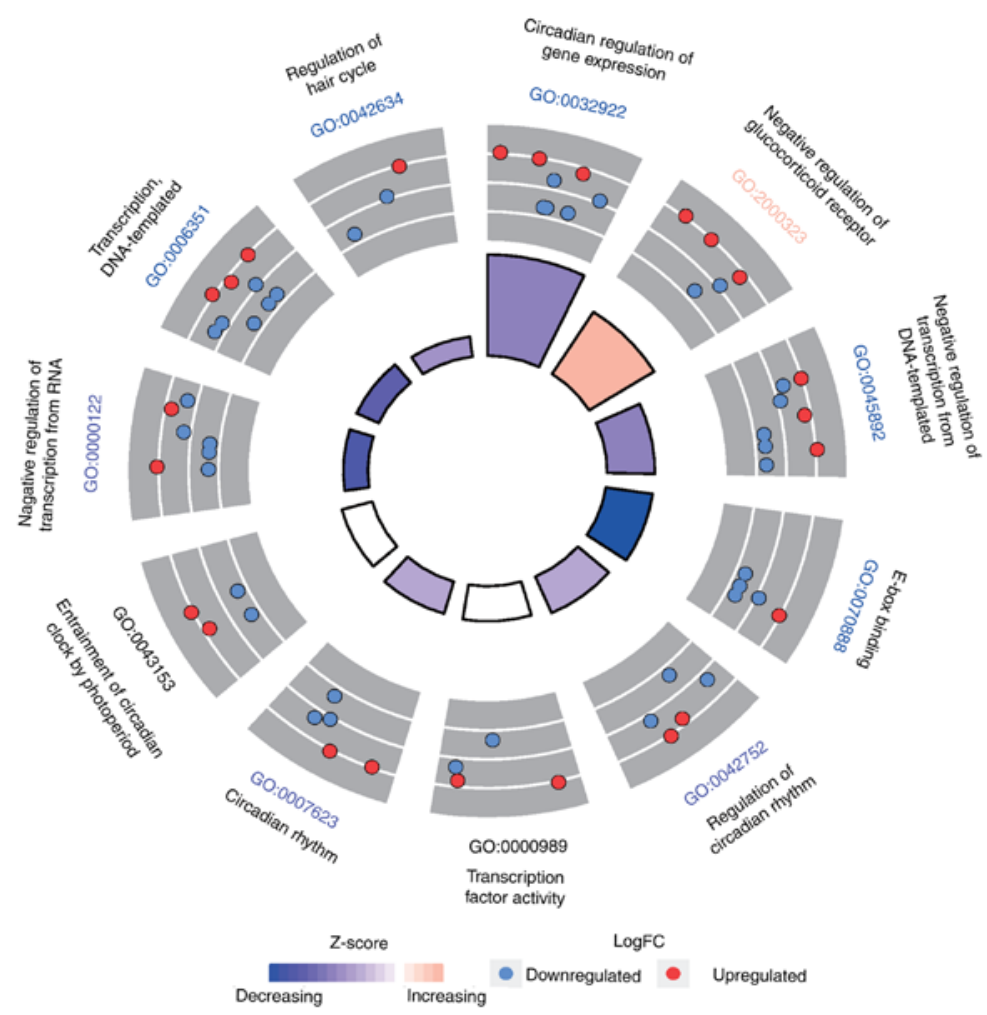

Figure 6. Functional characterization of differentially and rhythmically expressed protein-coding genes. GOCircle plot: The outer circle shows a scatter plot of the expression levels of rhythmically expressed clock-associated genes in each enriched GO term. Red circles indicate upregulation and blue circles indicate downregulation. The inner ring is a bar plot, where the height of the bar indicates the significance of the GO term (log10-adjusted P-value), and the color corresponds to the z-score: blue, decreased; red, increased; and white, unchanged. GO, Gene Ontology.

in rats to induce NS is between 5.0 and $7.5 \mathrm{mg} / \mathrm{kg}(16,45,46)$. Since complete absorption of the drug may induce organ damage, intravenous injection provides direct access to the drug and eliminates the absorption dependence on the 

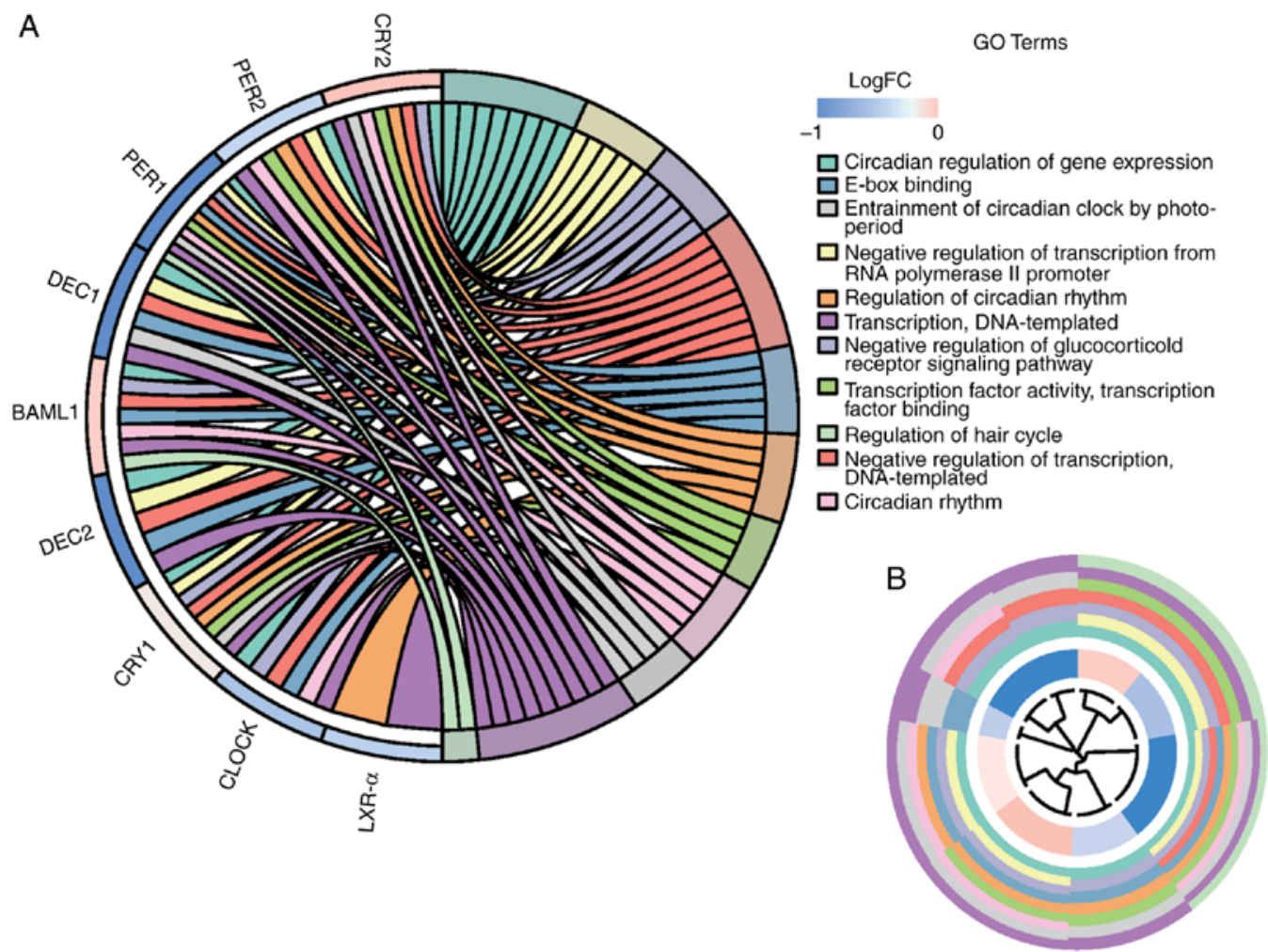

Figure 7. Specific clock genes are involved in pathways. (A) GOChord plot: A plot indicated the association between statistically significant clock genes and their associated GO terms; the genes are associated via ribbons to their assigned terms. Blue-to-red coding next to the selected genes indicates the amplitude change (the difference between the expression amplitude in the two groups divided by the amplitude of the control group). A negative sign indicates a decrease and a positive sign indicates an increase. The outer ring shows the assigned functional terms. (B) GOCluster plot: A circular dendrogram of the clustering of the expression profiles. The inner ring shows the color-coded amplitude changes and the outer ring shows the assigned functional terms. The details are provided in Table IV.

peritoneal membrane (46). Therefore, the present study used a single tail vein injection dose of $6.5 \mathrm{mg} / \mathrm{kg}$ the day after 2 weeks of adaptation and particular caution was taken due to the risk of extravasation during injection. The ADR-induced nephropathy rats exhibited significantly higher blood lipid levels and a disturbed blood lipid circadian rhythm $(\mathrm{P}<0.05)$. Notably, the activities of AST and ALT in the ADR group were not pathologically increased, whereby the levels were within the normal range of male rats aged 12-13 weeks (normal ranges: AST, 87-144 U/1; ALT, 28-40 U/l) (23). The NS rats in the present study may not have experienced deterioration in hepatic function, because the levels of ALT and AST remained within the normal range compared with the control group, and the total dose of Adriamycin was less than the dose required to induce liver damage. Dyslipidemia may be attributed to the compensatory liver dysfunction under the nephritic state. However, the lack of histological staining of liver tissue in the same set of experiments was a limitation of this study.

Multiple regulators of lipid metabolism and rate-limiting enzymes in TG accumulation exhibit circadian rhythmicity during nutrient metabolism, and the clock system is indispensable for these processes in the liver. Mice lacking the liver-specific core clock gene $B M A L 1$ exhibit abnormalities in blood TGs, GLU and gluconeogenesis. Furthermore, a previous study revealed the metabolism-associated clock-controlled genes altered rhythms; however, the rhythm of GLU remained consistent in the asynchronous dietary (47). Human plasma lipid levels, including those of TGs and cholesterol, are rhythmic over a 24-h period (48), independent of feeding and waking conditions (42). Furthermore, Chua et al (42) did not detect a circadian rhythm in blood GLU and LDL-C; however, a trend was observed for higher levels of LDL-C during the daytime, this may be due to substantial individual differences in timing of the rhythm. Their results are consistent with the present study; however, they did not evaluate a rhythmic component via the Fourier transform method. Significant daily variations in the HDL-C levels were detected by Rivera-Coll et al (48) and Van den Berg et al (49). However, Van Den Berg et al (49) did not evaluate a rhythmic component. Notably, different analytical methods in other studies make it difficult to compare the result that lack of circadian rhythm associated with HDL-C levels in the present study; a fact that may explain, in part, the observed differences in timing and daily amplitude between the present research and other studies. A previous study indicated CLOCK knockout mice exhibit hyperlipidemia and hepatic steatosis, and PERI regulates PPAR $\alpha$ mRNA expression and the development of obesity (41). Furthermore, $P E R 2$ has been suggested to be involved in PPAR-associated pathways and white adipose tissue mobilization (3). The aforementioned studies suggested that different circadian clock genes serve a role in the regulation of lipid regulation.

In the present study, the mRNA expression of six hepatic core clock genes in the normal control group was associated with stable rhythmic features, with minimums during the day and maximums at night (activity period), which is consistent with previous studies on mice $(50,51)$. Furthermore, the cycle 


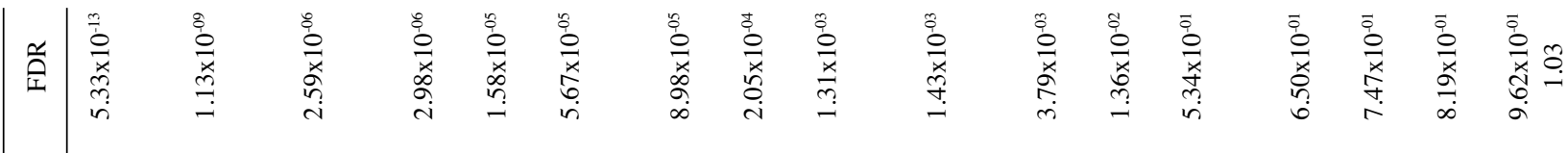

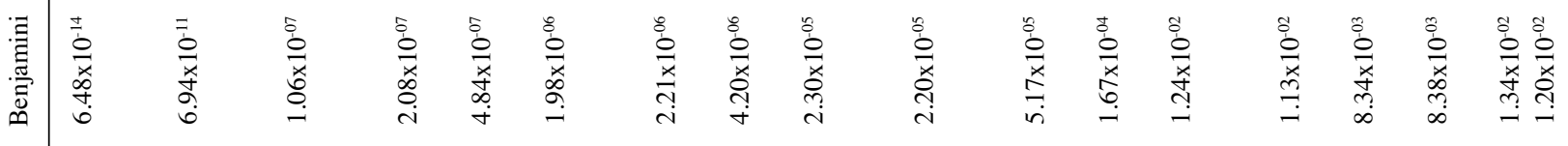

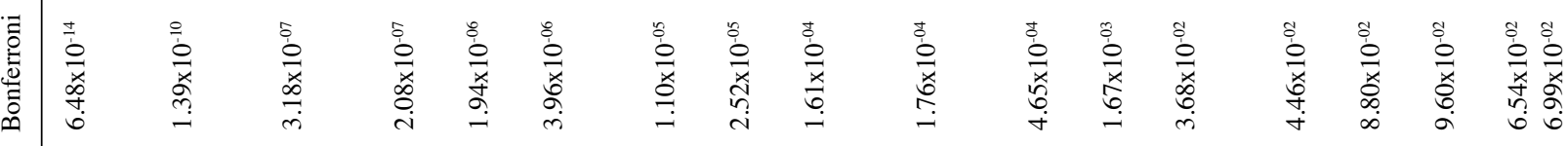

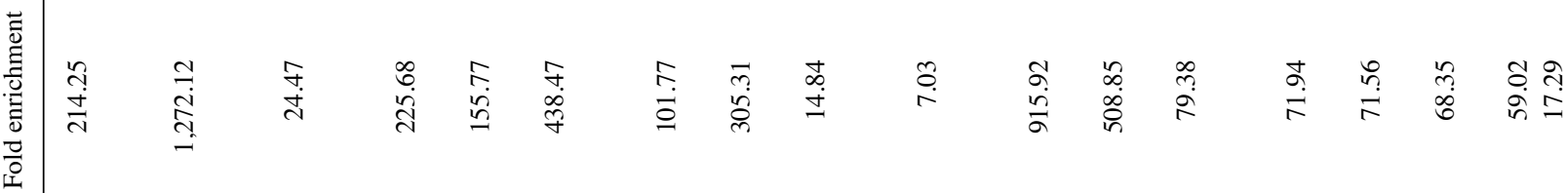

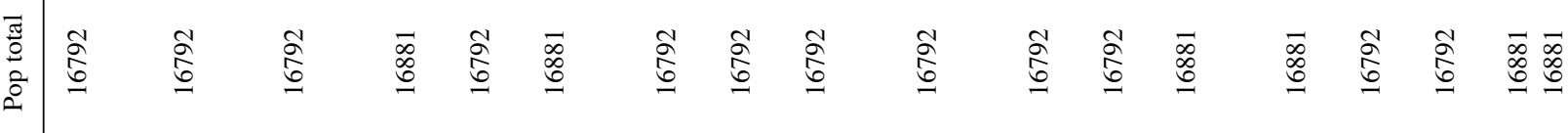

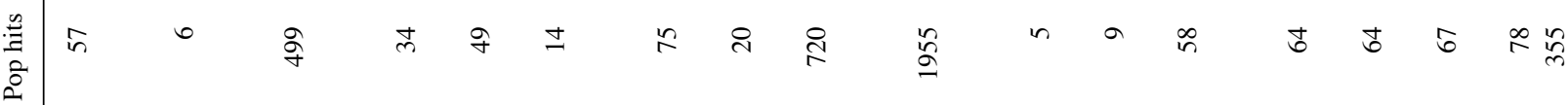

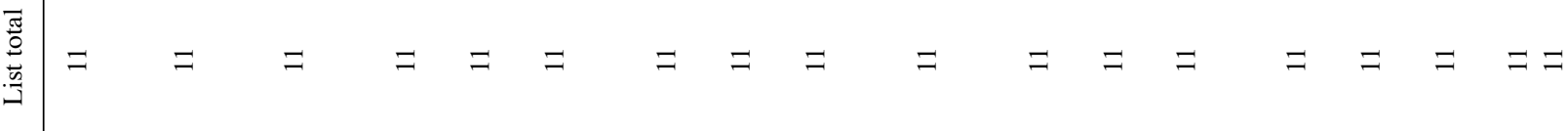

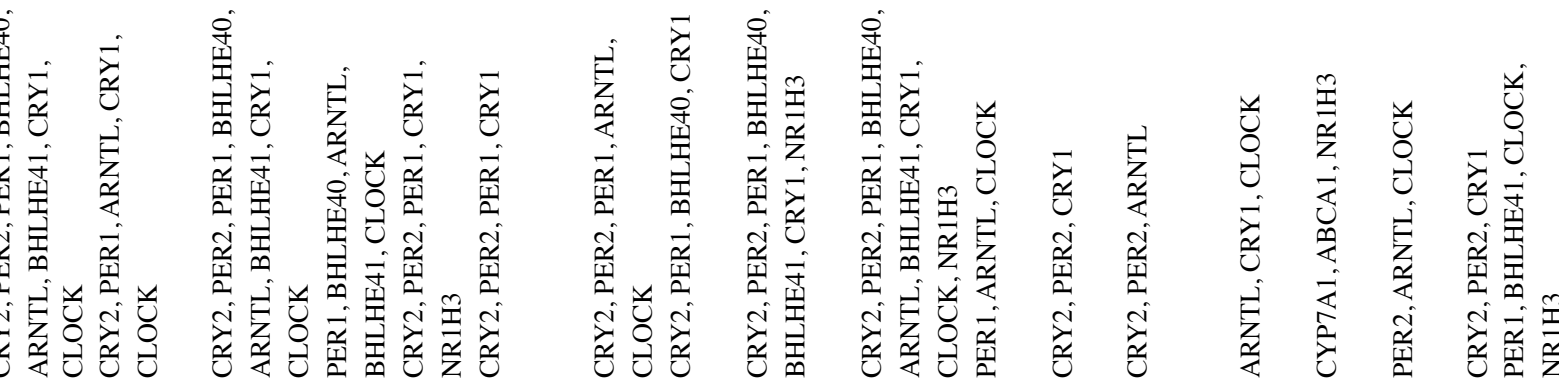

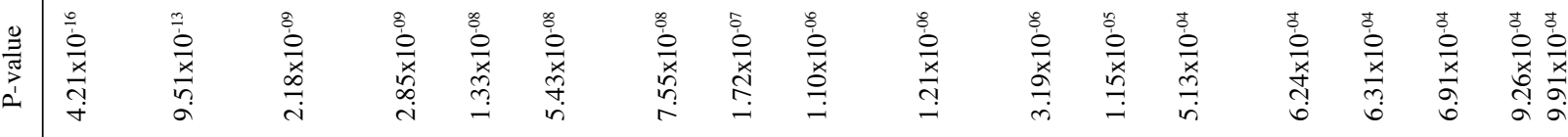

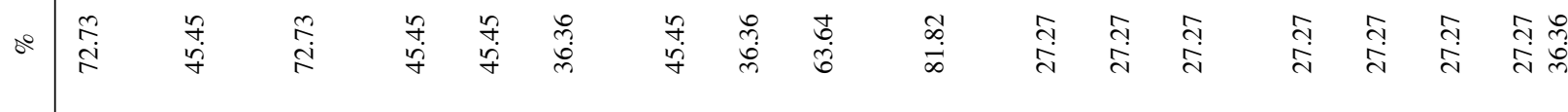

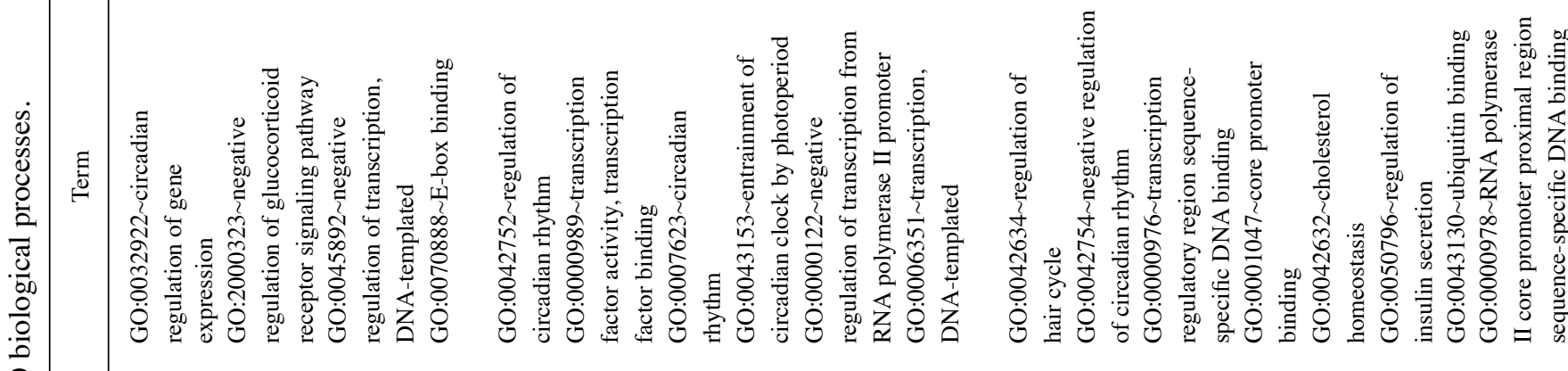

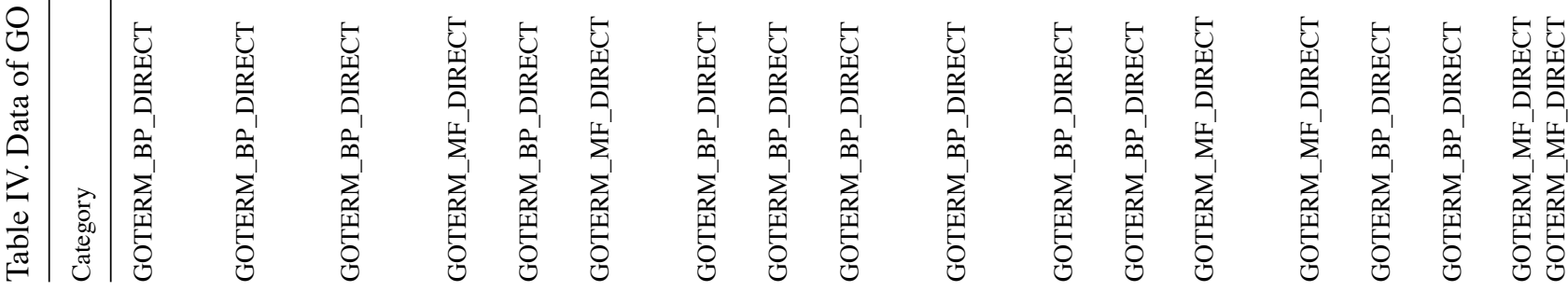




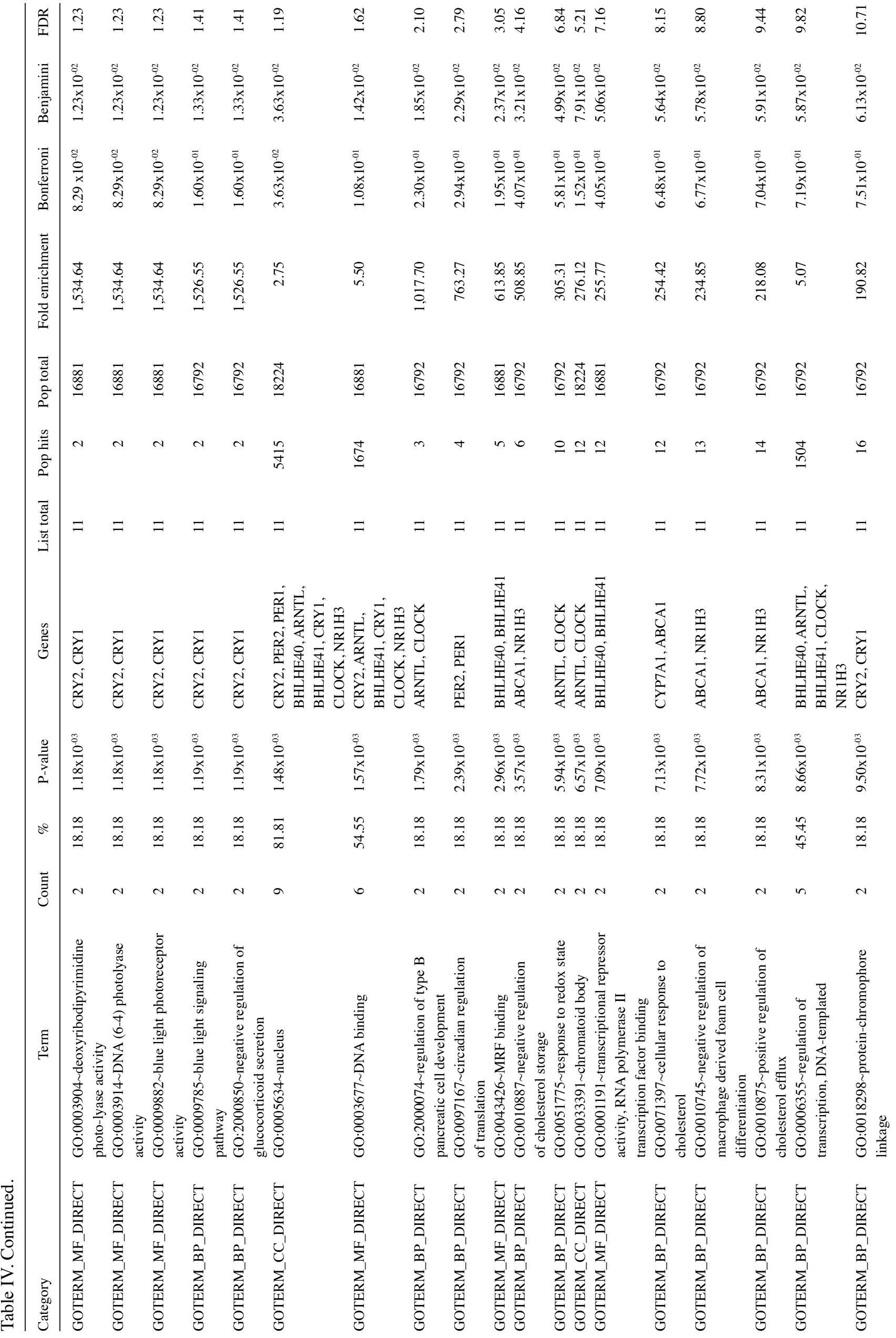




\begin{tabular}{|c|c|c|c|c|c|c|c|c|c|c|c|c|c|c|c|}
\hline 全 & ڤે & $\begin{array}{l}\stackrel{\infty}{\infty} \\
\stackrel{\sim}{\sim}\end{array}$ & $\stackrel{\vec{\jmath}}{\underline{g}}$ & $\stackrel{\vec{\jmath}}{\underline{g}}$ & 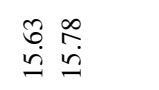 & $\begin{array}{l}\mathscr{\rho} \\
\stackrel{\infty}{=}\end{array}$ & 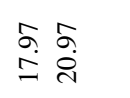 & 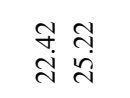 & 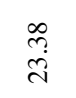 & 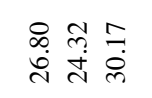 & $\begin{array}{l}\text { nे } \\
\text { nे }\end{array}$ & $\stackrel{\substack{n \\
i}}{i}$ & $\stackrel{+}{\stackrel{m}{m}}$ & $\sqrt[n]{n}$ & m. \\
\hline & \begin{tabular}{l}
0 \\
0 \\
0 \\
\multirow{x}{x}{} \\
0 \\
0
\end{tabular} & 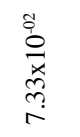 & $\begin{array}{l}0 \\
0 \\
0 \\
x \\
0 \\
\infty \\
\infty\end{array}$ & $\begin{array}{l}0 \\
0 \\
0 \\
x \\
0 \\
\infty \\
\infty\end{array}$ & 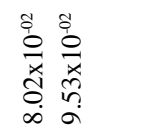 & 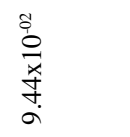 & 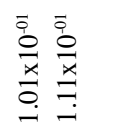 & 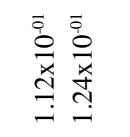 & 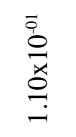 & 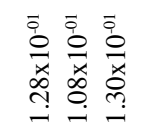 & 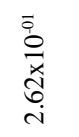 & 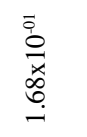 & 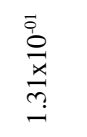 & 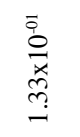 & $\stackrel{\substack{x\\
}}{r}$ \\
\hline & 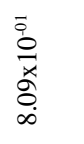 & $\begin{array}{l}\bar{a} \\
\stackrel{0}{x} \\
0 \\
0 \\
\infty\end{array}$ & 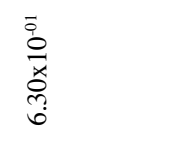 & 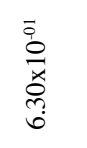 & 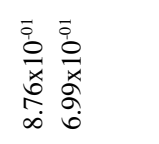 & 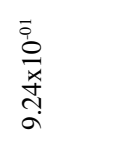 & 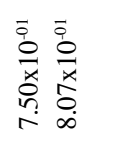 & 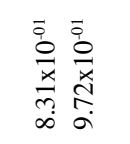 & 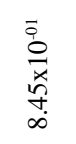 & 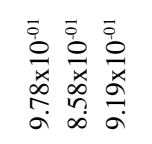 & 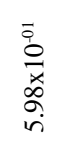 & 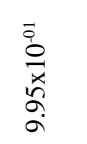 & $\begin{array}{l}\overline{\bar{a}} \\
\frac{0}{x} \\
\underline{m} \\
a\end{array}$ & $\begin{array}{l}\bar{a} \\
\stackrel{0}{x} \\
\stackrel{x}{\sigma} \\
\stackrel{\sigma}{\alpha}\end{array}$ & $\begin{array}{l}\bar{x} \\
\vdots \\
a\end{array}$ \\
\hline 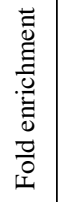 & $\begin{array}{l}\text { oे } \\
\stackrel{0}{0}\end{array}$ & $\begin{array}{l}\text { के } \\
\text { pे }\end{array}$ & $\stackrel{?}{\stackrel{n}{m}}$ & 年 & 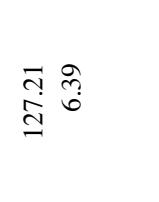 & तิ่ & 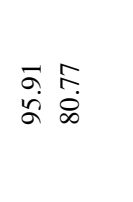 & 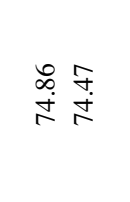 & $\stackrel{\infty}{\stackrel{\infty}{R}}$ & 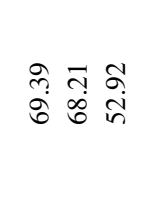 & $\bar{\infty}$ & $\begin{array}{l}\infty \\
\infty \\
\infty\end{array}$ & $\begin{array}{l}\infty \\
\infty \\
\infty\end{array}$ & 量 & \\
\hline $\begin{array}{l}\frac{\pi}{0} \\
0 \\
0\end{array}$ & $\widehat{\hat{\hat{\sigma}}}$ & م્ડ & $\begin{array}{l}\vec{\infty} \\
\stackrel{0}{0} \\
\stackrel{0}{0}\end{array}$ & $\begin{array}{l}\overrightarrow{0} \\
\stackrel{0}{o} \\
\stackrel{0}{a}\end{array}$ & 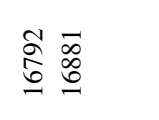 & م્ડે & 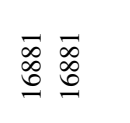 & 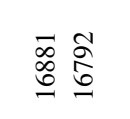 & $\begin{array}{l}\vec{\infty} \\
\stackrel{0}{0} \\
\stackrel{0}{0}\end{array}$ & 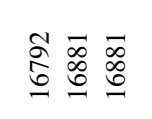 & 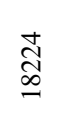 & م્ડ & $\begin{array}{l}\vec{\infty} \\
\stackrel{\infty}{0} \\
\stackrel{0}{0}\end{array}$ & $\begin{array}{l}\overrightarrow{\bar{o}} \\
\stackrel{0}{0} \\
-\end{array}$ & ๙ิ \\
\hline 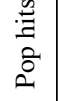 & $\stackrel{2}{ }$ & $\vec{\sim}$ & $\tilde{\lambda}$ & $\tilde{\imath}$ & ন্ঠ & $\vec{\infty}$ & $\aleph^{1} \stackrel{\infty}{\infty}$ & $F F$ & $\stackrel{q}{f}$ & $f$ if & $i_{n}^{\infty}$ & $\frac{n}{n}$ & $\stackrel{\infty}{n}$ & 8 & \\
\hline & $=$ & $=$ & $=$ & $=$ & $==$ & $=$ & $==$ & $==$ & $=$ & $==$ & $=$ & $=$ & $=$ & $=$ & \\
\hline 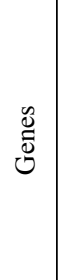 & 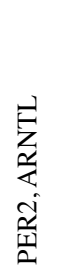 & 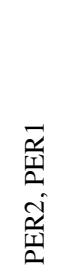 & 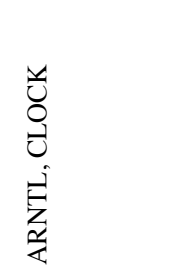 & 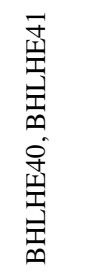 & 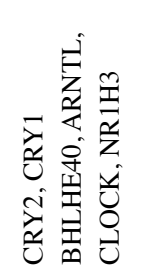 & 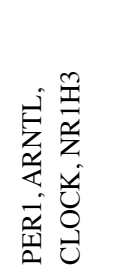 & 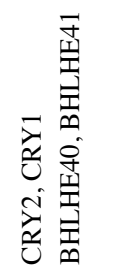 & 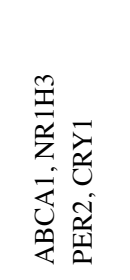 & 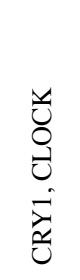 & 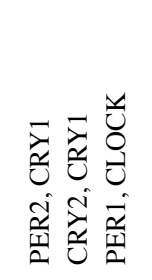 & 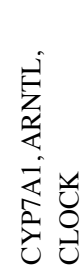 & 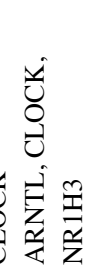 & 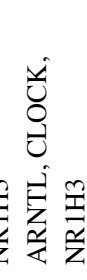 & 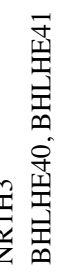 & $\underset{\mathbb{Z}}{\simeq}$ \\
\hline D & 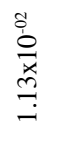 & 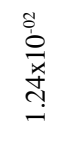 & 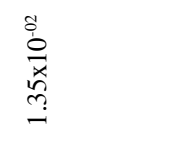 & 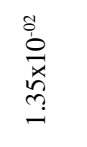 & 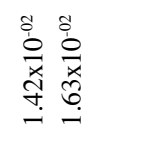 & 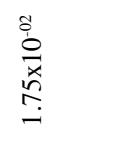 & 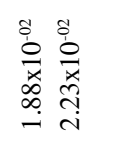 & 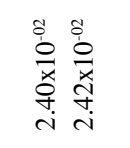 & 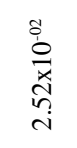 & 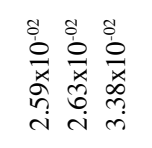 & 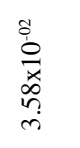 & 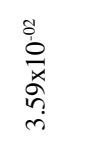 & 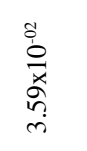 & 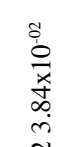 & ๙্য \\
\hline$\delta^{\circ}$ & $\begin{array}{l}\infty \\
\infty \\
\infty\end{array}$ & $\stackrel{\infty}{\infty}$ & $\stackrel{\infty}{\infty}$ & $\stackrel{\infty}{\stackrel{\infty}{-}}$ & $\begin{array}{l}\infty \\
\stackrel{\infty}{\infty} \\
\stackrel{\infty}{\infty} \\
\stackrel{n}{\infty}\end{array}$ & 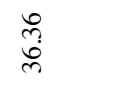 & $\begin{array}{ll}\infty & \infty \\
\infty & \stackrel{\infty}{\infty} \\
\stackrel{\infty}{\sim}\end{array}$ & $\begin{array}{ll}\infty & \infty \\
\stackrel{\infty}{\infty} & \stackrel{\infty}{\infty} \\
\stackrel{\infty}{\sim}\end{array}$ & $\stackrel{\infty}{\infty}$ & 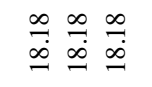 & 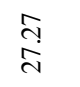 & 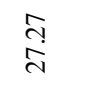 & 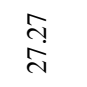 & $\begin{array}{l}\infty \\
\infty \\
\infty\end{array}$ & $\stackrel{\infty}{\stackrel{\infty}{\infty}}$ \\
\hline 言 & $N$ & N & N & $N$ & & $\nabla$ & $\mathrm{N} N$ & $N \mathrm{~N}$ & N & $N \sim N$ & $m$ & $m$ & $m$ & $N$ & \\
\hline 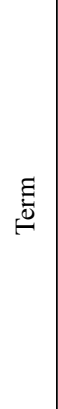 & 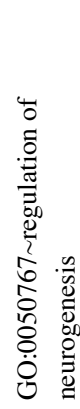 & 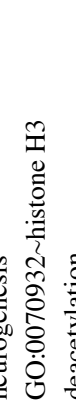 & 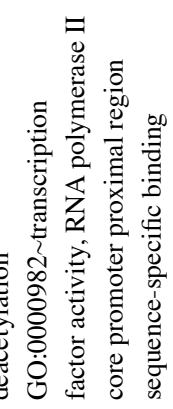 & 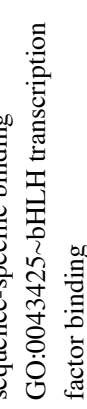 & 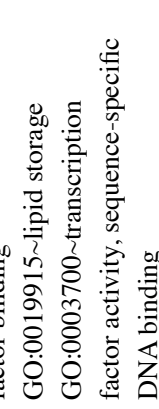 & 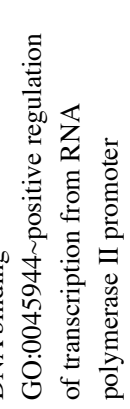 & 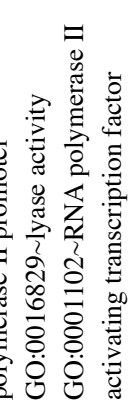 & 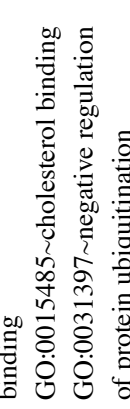 & 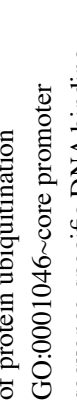 & 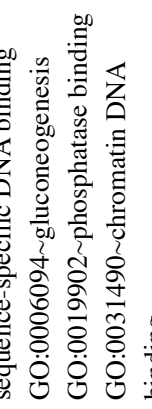 & 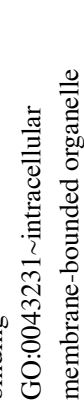 & 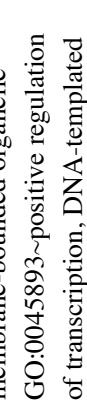 & 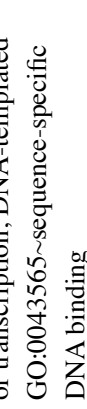 & \multicolumn{2}{|c|}{ 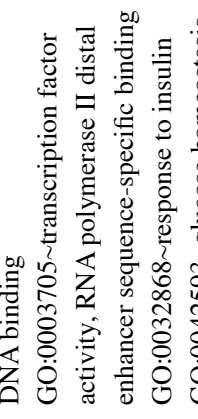 } \\
\hline 突 & 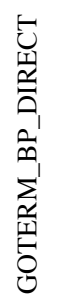 & 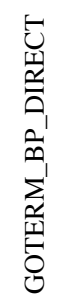 & 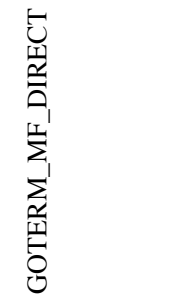 & 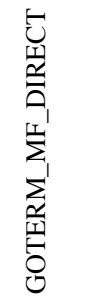 & 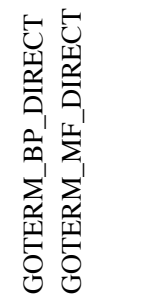 & 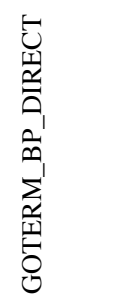 & 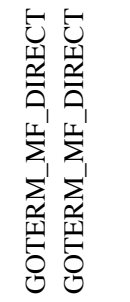 & 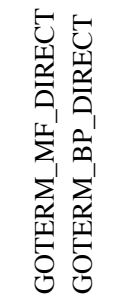 & 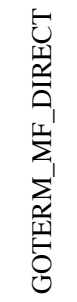 & 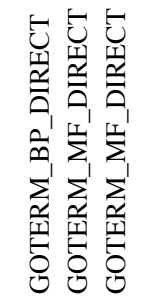 & 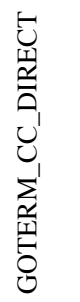 & 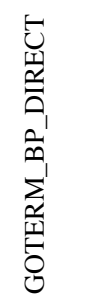 & 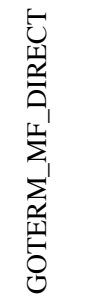 & 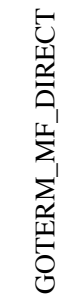 & 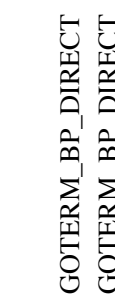 \\
\hline
\end{tabular}


duration was $24 \mathrm{~h}$ for five core clock genes (CLOCK, BMAL1, PER2, CRY1 and CRY2) and $12 \mathrm{~h}$ for PER1 in the control group. However, extended or abnormal rhythms were exhibited in the ADR group. Although PER 1 mRNA was expressed in the ADR group, the rhythm was absent $(\mathrm{P}<0.05)$. In addition, disordered rhythms were revealed in the downstream lipid-associated clock-controlled genes of core hepatic clock genes (LXR, DECl, DEC2, SREBP-1, ABCA1 and CYP7A1). Among these, the rhythmic expression of functional clock genes (DEC1 and $D E C 2)$, as well as PERl, was entirely absent in the ADR group. Notably, the former two genes are downstream of the core clock gene PERI and regulate feedback of $P E R 1$ transcription (52). CYP7A1, SREBP-1 and ABCA1 all exhibit periodic oscillations, and are regulated by $D E C l$ and $D E C 2$ (53). CYP7 $\alpha$ serves important roles in bile acid synthesis and its rhythmic expression is inhibited by binding DEC2 via E-box elements. The present finding supports that increasing hepatic $D E C 2$ mRNA expression may result in a reduction in CYP7 $\alpha$ mRNA expression in NS rats. This may hinder the metabolism of cholesterol into bile acids, thereby inducing the occurrence of hypercholesterolemia. LXR $\alpha$ increases $C Y P 7 \alpha$ expression and promotes bile acid synthesis (54). ABCA1 typically mediates the transmembrane transport of lipids metabolites (55), serving a key role in the reverse transport of cholesterol in vivo. It also permits intracellular cholesterol, phospholipid and free ApoA or ApoE binding to LXR $\alpha$, which then initiates HDL synthesis. In addition, several fatty acid synthase genes are target genes of SREBP-1, and the activity of SREBP-1 leads to an increase in blood TG synthesis. The present study indicated that the circadian rhythmic expression of lipid metabolism genes was regulated by the critical rhythm of key enzymes and transcription-associated factors, and the associated fat synthase gene was simultaneously activated by the core clock genes (Fig. 9).

Due to the limitation that human liver tissue cannot be extracted six times within $24 \mathrm{~h}$ to monitor blood lipid rhythm analysis, GO and KEGG enrichment assays were performed to detect differentially expressed clock genes to provide a biologically meaningful explanation of the present results in humans. Using bioinformatics methods, including the GOplot $\mathrm{R}$ package, for visually combining expression data with functional analysis and predicting the potential disease-causing genes has been considered viable in various diseases $(56,57)$. The enrichment of GO annotation terms revealed that the clock system protein-coding genes were significantly enriched in specific biological processes, MFs and CCs. In particular, the most representative functional processes of clock genes were the circadian regulation of gene expression, E-box binding, transcription factor activity and negative regulation of the glucocorticoid receptor signaling pathway. These findings were consistent with previous evidence that suggest the essential role of these pathogenetic mechanisms in disease states $(4,5,9)$. However, the most significant limitation of the current research is the observational nature of the study in vivo, and the lack of specific knockdown and response experiments.

The functional interpretation of the GO- and KEGG-based clock-specific 'concept-and-gene networks' in the present study highlighted the possibility that core clock genes exert pathogenic effects via different multifactorial combinations, providing an important insight into clock core 

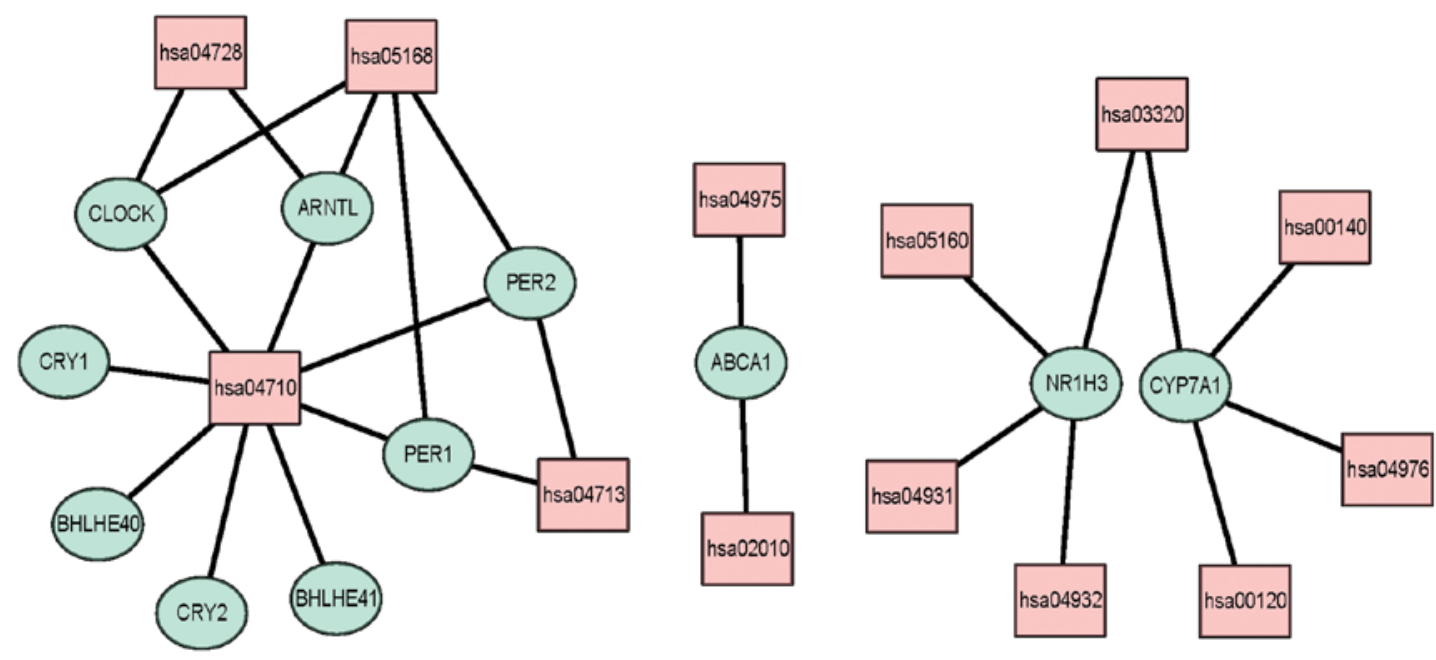

Figure 8. KEGG analysis was conducted using KOBAS 3.0 online software (http://kobas.cbi.pku.edu.cn/). KEGG pathway enrichment of significant rhythmically expressed protein-coding genes. The green node represents significant rhythmically expressed protein-coding genes. The red node represents enriched pathway symbols. The details are provided in Table V. KEGG, Kyoto Encyclopedia of Genes and Genomes.

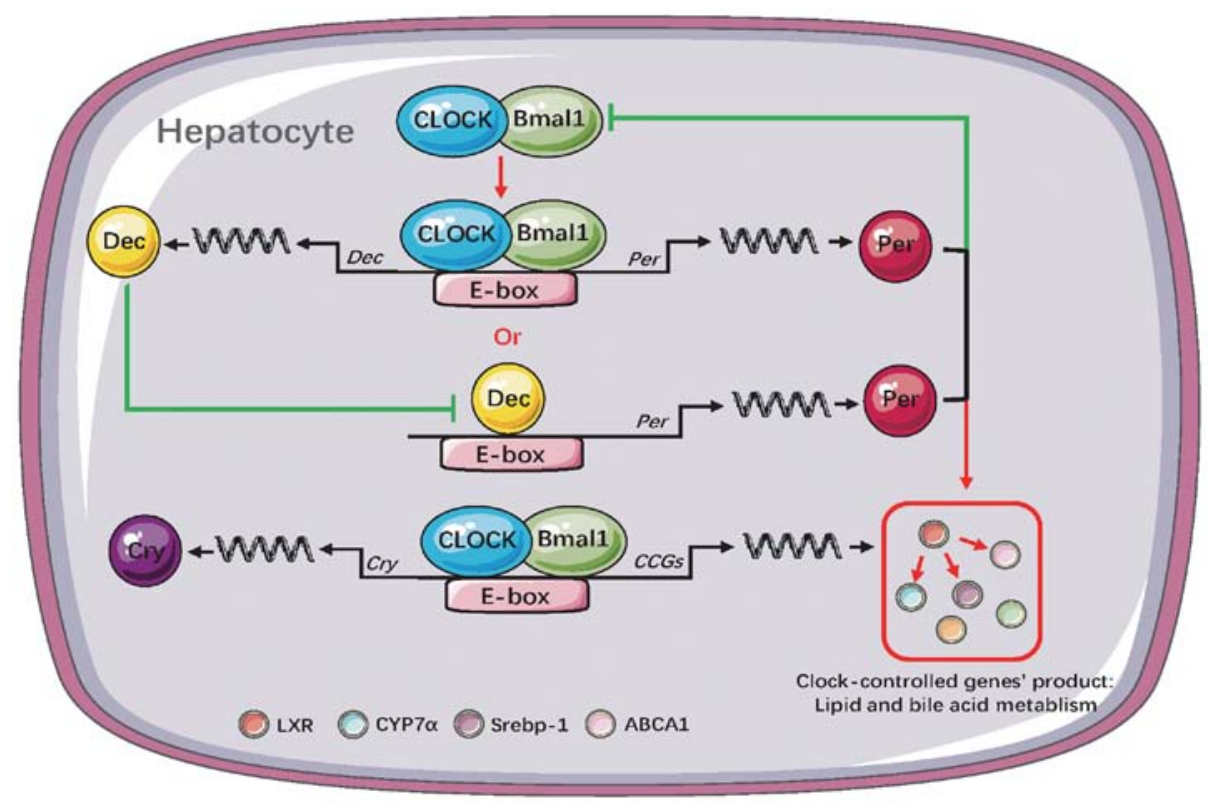

Figure 9. Diagram of liver clock gene and clock control gene association. The red line represents the promoting effect, the green line represents inhibition, and the black line represents transcription into protein. $C L O C K$, circadian locomoter output cycles kaput; BMAL1, brain and muscle ARNT-like protein 1; $C R Y$, cryptochrome; PER, period homologue; $L X R$, liver X receptor; $C Y P 7 A 1$, cholesterol $7 \alpha$-hydroxylase; SREBP-1, sterol regulatory element binding protein-1c; $A B C A 1$, ATP binding cassette transporter A1; DEC, differentiated embryo chondrocyte.

genes that may have a fundamental influence in NS. The transcriptional amplitude of clock genes was decreased or absent in patients with NS included in this study, suggesting that these proteins may represent susceptibility factors for disordered rhythms.

To compensate for the difficulties and limitations of human circadian rhythm research, multiple bioinformatics methods were used to analyze the associations between the overall human core clock (BMAL1, CLOCK, CRY1, CRY2, PER1 and $P E R 2)$ and clock-controlled genes (LXR, DECl, DEC2, $S R E B P-1, A B C A 1$ and $C Y P 7 A 1$ ), including signaling pathway and correlation prediction analyses. Their associations in the co-expression network were determined (avg. local clustering coefficient, 0.849 ). Consistent with the KEGG pathway analysis results, these genes were primarily enriched in the circadian rhythm pathway, and governed the regulation of downstream liver-specific, lipid-associated clock-controlled genes and blood lipid homeostasis and rhythmicity. These results may aid in providing a deeper understanding of rhythmic gene expression in the human clock system.

From the publications reviewed, NS is one of the few acquired conditions that alter the plasma levels of lipoprotein (58). Once NS enters remission, lipoprotein levels normalize quickly (38), and the changes in hepatic circadian rhythm were demonstrated to be secondary to kidney disease without any damage to liver tissue in the present study. Since the molecular mechanism of the circadian rhythm of an organism involves the clock gene system, and the activity of 


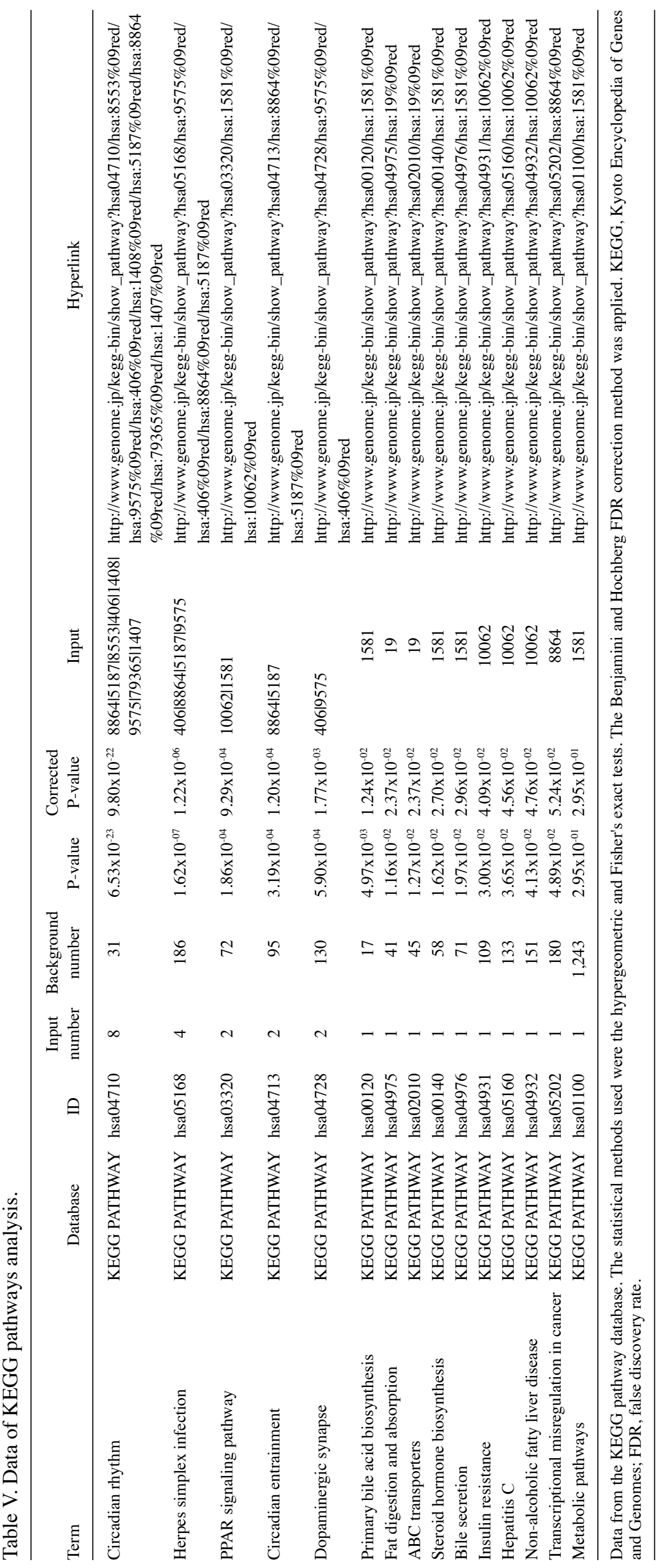


peripheral clock systems are independent from the central clock system, the present study results suggested that renal injury lead to local circadian system disorder, which may have caused the impaired function of the core clock gene to affect the liver, subsequently disrupting lipid metabolism. In order to confirm the phenomenon observed in the present study, further studies are required.

In conclusion, the present study reported that NS rats exhibited dyslipidemia and circadian disorders of lipid metabolism. The results suggested that these changes involve the abnormal expression of hepatic core clock genes and downstream clock-controlled genes. Furthermore, the findings indicated that damage to the hepatic clock system is a potential molecular mechanism for disordered blood lipid circadian rhythm in the context of CKD. Such analyses offer a starting point for understanding the crosstalk between peripheral organs and peripheral clock systems. Further investigations into the prevention and treatment of CKD by resetting or repairing disturbed central or peripheral clock systems are required.

\section{Acknowledgements}

Not applicable.

\section{Funding}

The present study was supported by the National Natural Sciences Foundation of China (grant no. 81100545), The Beijing Municipal Science and Technology Commission (grant nos. D131100004713007 and D09050704310901), and The Peking Union Medical College Youth Fund (grant no. 3332016012).

\section{Availability of data and materials}

All data generated or analyzed during this study are included in this published article.

\section{Authors' contributions}

PC, RZ, LM, XwL, XmL and YQ contributed to the conception and design of this study. PC, RZ and LM performed the experiments. PC analyzed and interpretation of data. PC and YQ drafted the manuscript. All the authors read and gave final approval of the version to be published.

\section{Ethics approval and consent to participate}

The animal experimental procedures were approved by the Animal Ethics Committee of Peking Union Medical College Hospital (Beijing, China).

\section{Patient consent for publication}

Not applicable.

\section{Competing interests}

The authors declare that they have no competing interests.

\section{References}

1. Harper CR and Jacobson TA: Managing dyslipidemia in chronic kidney disease. J Am Coll Cardiol 51: 2375-2384, 2008

2. Tsimihodimos V, Dounousi E and Siamopoulos KC: Dyslipidemia in chronic kidney disease: An approach to pathogenesis and treatment. Am J Nephrol 28: 958-973, 2008.

3. Zhao X, Cho H, Yu RT, Atkins AR, Downes M and Evans RM: Nuclear receptors rock around the clock. EMBO Rep 15: 518-528, 2014.

4. Zhang EE and Kay SA: Clocks not winding down: Unravelling circadian networks. Nat Rev Mol Cell Biol 11: 764-776, 2010.

5. Ungar F and Halberg F: Circadian rhythm in the in vitro response of mouse adrenal to adrenocorticotropic hormone. Science 137: 1058-1060, 1962.

6. Mure LS, Le HD, Benegiamo G, Chang MW, Rios L, Jillani N, Ngotho M, Kariuki T, Dkhissi-Benyahya O, Cooper HM and Panda S: Diurnal transcriptome atlas of a primate across major neural and peripheral tissues. Science 359: eaao0318, 2018.

7. Tokonami N, Mordasini D, Pradervand S, Centeno G, Jouffe C, Maillard M, Bonny O, Gachon F, Gomez RA, Sequeira-Lopez ML and Firsov D: Local renal circadian clocks control fluid-electrolyte homeostasis and BP. J Am Soc Nephrol 25: 1430-1439, 2014.

8. Reppert SM and Weaver DR: Coordination of circadian timing in mammals. Nature 418: 935-941, 2002.

9. Oosterman JE, Kalsbeek A, la Fleur SE and Belsham DD: Impact of nutrients on circadian rhythmicity. Am J Physiol Regul Integr Comp Physiol 308: R337-R350, 2015.

10. Wharfe MD, Mark PJ and Waddell BJ: Circadian variation in placental and hepatic clock genes in rat pregnancy. Endocrinology 152: 3552-3560, 2011.

11. Touitou Y, Smolensky MH and Portaluppi F: Ethics, standards, and procedures of animal and human chronobiology research. Chronobiol Int 23: 1083-1096, 2006.

12. Nguyen TT, Mattick JS, Yang Q, Orman MA, Ierapetritou MG, Berthiaume $\mathrm{F}$ and Androulakis IP: Bioinformatics analysis of transcriptional regulation of circadian genes in rat liver. BMC Bioinformatics 15: 83, 2014.

13. Wu T, ZhuGe F, Zhu Y, Wang N, Jiang Q, Fu H, Li Y and Fu Z: Effects of light on the circadian rhythm of diabetic rats under restricted feeding. J Physiol Biochem 70: 61-71, 2014.

14. Bertani T, Poggi A, Pozzoni R, Delaini F, Sacchi G, Thoua Y, Mecca G, Remuzzi G and Donati MB: Adriamycin-induced nephrotic syndrome in rats: Sequence of pathologic events. Lab Invest 46: 16-23, 1982.

15. Lu B, Li X and Ma R: Evaluation of the modified adriamycin induced nephrotic rats. Lab Anim Sci Admin 16: 5-9, 1999 (In Chinese).

16. Pereira Wde F, Brito-Melo GE, de Almeida CA, Moreira LL, Cordeiro CW, Carvalho TG, Mateo EC, Simões E and Silva AC: The experimental model of nephrotic syndrome induced by Doxorubicin in rodents: An update. Inflamm Res 64: 287-301, 2015.

17. Brainard GC, Richardson BA, King TS and Reiter RJ: The influence of different light spectra on the suppression of pineal melatonin content in the Syrian hamster. Brain Res 294: 333-339, 1984.

18. Trinder P and Webster D: Determination of HDL-cholesterol using 2,4,6-tribromo-3-hydroxybenzoic acid with a commercial CHOD-PAP reagent. Ann Clin Biochem 21: 430-433, 1984.

19. Friedewald WT, Levy RI and Fredrickson DS: Estimation of the concentration of low-density lipoprotein cholesterol in plasma, without use of the preparative ultracentrifuge. Clin Chem 18: 499-502, 1972.

20. Westgard JO and Poquette MA: Determination of serum albumin with the 'SMA $12-60$ ' by a bromcresol green dye-binding method. Clin Chem 18: 647-653, 1972.

21. Fossati P, Prencipe L and Berti G: Enzymic creatinine assay: A new colorimetric method based on hydrogen peroxide measurement. Clin Chem 29: 1494-1496, 1983.

22. Neeley WE: Simple automated determination of serum or plasma glucose by a hexokinase-glucose-6-phosphate dehydrogenase method. Clin Chem 18: 509-515, 1972.

23. Livak KJ and Schmittgen TD: Analysis of relative gene expression data using real-time quantitative PCR and the 2(-Delta Delta C(T)) method. Methods 25: 402-408, 2001.

24. Szklarczyk D, Franceschini A, Kuhn M, Simonovic M, Roth A, Minguez P, Doerks T, Stark M, Muller J, Bork P, et al: The STRING database in 2011: Functional interaction networks of proteins, globally integrated and scored. Nucleic Acids Res 39: D561-D568, 2011. 
25. Huang da W, Sherman BT and Lempicki RA: Bioinformatics enrichment tools: Paths toward the comprehensive functional analysis of large gene lists. Nucleic Acids Res 37: 1-13, 2009.

26. Shannon P, Markiel A, Ozier O, Baliga NS, Wang JT, Ramage D, Amin N, Schwikowski B and Ideker T: Cytoscape: A software environment for integrated models of biomolecular interaction networks. Genome Res 13: 2498-2504, 2003.

27. Walter W, Sánchez-Cabo F and Ricote M: GOplot: An R package for visually combining expression data with functional analysis. Bioinformatics 31: 2912-2914, 2015.

28. Paul T and Lemmer B: Disturbance of circadian rhythms in analgosedated intensive care unit patients with and without craniocerebral injury. Chronobiol Int 24: 45-61, 2007.

29. Palma-Rigo K, Baudrie V, Laude D, Petrel C, Clauser E and Elghozi JL: Cardiovascular rhythms and cardiac baroreflex sensitivity in AT(1A) receptor gain-of-function mutant mice. Chronobiol Int 27: 128-137, 2010.

30. Lee VW and Harris DC: Adriamycin nephropathy: A model of focal segmental glomerulosclerosis. Nephrology (Carlton) 16 30-38, 2011.

31. Mamdani M, Williamson V, McMichael GO, Blevins T, Aliev F, Adkins A, Hack L, Bigdeli T, van der Vaart AD, Web BT, et al: Integrating mRNA and miRNA weighted gene co-expression networks with eQTLs in the nucleus accumbens of subjects with alcohol dependence. PLoS One 10: e0137671, 2015.

32. Szklarczyk D, Morris JH, Cook H, Kuhn M, Wyder S, Simonovic M, Santos A, Doncheva NT, Roth A, Bork P, et al: The STRING database in 2017: Quality-controlled protein-protein association networks, made broadly accessible. Nucleic Acids Res 45: D362-D368, 2017.

33. Szklarczyk D, Franceschini A, Wyder S, Forslund K, Heller D, Huerta-Cepas J, Simonovic M, Roth A, Santos A, Tsafou KP, et al: STRING v10: Protein-protein interaction networks, integrated over the tree of life. Nucleic Acids Res 43 (Database Issue): D447-D452, 2015.

34. Huang da W, Sherman BT and Lempicki RA: Systematic and integrative analysis of large gene lists using DAVID bioinformatics resources. Nat Protoc 4: 44-57, 2009.

35. Feng G, Shaw P, Rosen ST, Lin SM and Kibbe WA: Using the bioconductor GeneAnswers package to interpret gene lists. Methods Mol Biol 802: 101-112, 2012.

36. Wahl P, Ducasa GM and Fornoni A: Systemic and renal lipids in kidney disease development and progression. Am J Physiol Renal Physiol 310: F433-F445, 2016.

37. Rogacev KS, Pinsdorf T, Weingärtner O, Gerhart MK, Welzel E, van Bentum K, Popp J, Menzner A, Fliser D, Lütjohann D and Heine GH: Cholesterol synthesis, cholesterol absorption, and mortality in hemodialysis patients. Clin J Am Soc Nephrol 7: 943-948, 2012

38. Kaysen GA: Nonrenal complications of the nephrotic syndrome. Ann Rev Med 45: 201-210, 1994.

39. Schalk BW, Visser M, Deeg DJ and Bouter LM: Lower levels of serum albumin and total cholesterol and future decline in functional performance in older persons: The Longitudinal Aging Study Amsterdam. AGE Ageing 33: 266-272, 2004

40. Lamia KA, Storch KF and Weitz CJ: Physiological significance of a peripheral tissue circadian clock. Proc Natl Acad Sci USA 105: 15172-15177, 2008.

41. Richards J, All S, Skopis G, Cheng KY, Compton B, Srialluri N, Stow L, Jeffers LA and Gumz ML: Opposing actions of Per1 and Cry 2 in the regulation of Perl target gene expression in the liver and kidney. Am J Physiol Regul Integr Comp Physiol 305 R735-R747, 2013.

42. Chua EC, Shui G, Lee IT, Lau P, Tan LC, Yeo SC, Lam BD, Bulchand S, Summers SA, Puvanendran K, et al: Extensive diversity in circadian regulation of plasma lipids and evidence for different circadian metabolic phenotypes in humans. Proc Natl Acad Sci USA 110: 14468-14473, 2013.

43. Nikolaeva S, Pradervand S, Centeno G, Zavadova V, Tokonami N, Maillard M, Bonny O and Firsov D: The circadian clock modulates renal sodium handling. J Am Soc Nephrol 23: 1019-1026, 2012.
44. Hou XW, Jiang Y, Wang LF, Xu HY, Lin HM, He XY, He JJ and Zhang S: Protective role of granulocyte colony-stimulating factor against adriamycin induced cardiac, renal and hepatic toxicities. Toxicol Lett 187: 40-44, 2009.

45. Bertani T, Cutillo F, Zoja C, Broggini M and Remuzzi G: Tubulo-interstitial lesions mediate renal damage in adriamycin glomerulopathy. Kidney Int 30: 488-496, 1986.

46. Pippin JW, Brinkkoetter PT, Cormack-Aboud FC, Durvasula RV, Hauser PV, Kowalewska J, Krofft RD, Logar CM, Marshall CB Ohse T and Shankland SJ: Inducible rodent models of acquired podocyte diseases. Am J Physiol Renal Physiol 296: F213-F229, 2009.

47. Rudic RD, McNamara P, Curtis AM, Boston RC, Panda S, Hogenesch JB and Fitzgerald GA: BMAL1 and CLOCK, two essential components of the circadian clock, are involved in glucose homeostasis. PLoS Biol 2: e377, 2004.

48. Rivera-Coll A, Fuentes-Arderiu X and Diez-Noguera A: Circadian rhythmic variations in serum concentrations of clinically important lipids. Clin Chem 40: 1549-1553, 1994.

49. Van den Berg R, Noordam R, Kooijman S, Jansen SWM Akintola AA, Slagboom PE, Pijl H, Rensen PCN, Biermasz NR and van Heemst D: Familial longevity is characterized by high circadian rhythmicity of serum cholesterol in healthy elderly individuals. Aging cell 16: 237-243, 2017.

50. Fonken LK, Aubrecht TG, Meléndez-Fernández OH, Weil ZM and Nelson RJ: Dim light at night disrupts molecular circadian rhythms and increases body weight. J Biol Rhythms 28: 262-271, 2013.

51. Baeza-Raja B, Eckel-Mahan K, Zhang L, Vagena E, Tsigelny IF, Sassone-Corsi P, Ptácek LJ and Akassoglou K: p75 neurotrophin receptor is a clock gene that regulates oscillatory components of circadian and metabolic networks. J Neurosci 33: 10221-10234, 2013.

52. Honma S, Kawamoto T, Takagi Y, Fujimoto K, Sato F, Noshiro M, Kato Y and Honma K: Dec1 and Dec2 are regulators of the mammalian molecular clock. Nature 419: 841-844, 2002.

53. Kato $Y$, Kawamoto $T$, Fujimoto $K$ and Noshiro $M$ : DEC1/STRA13/SHARP2 and DEC2/SHARP1 coordinate physiological processes, including circadian rhythms in response to environmental stimuli. Curr Top Dev Biol 110: 339-372, 2014.

54. Edwards PA, Kast HR and Anisfeld AM: BAREing it all: The adoption of LXR and FXR and their roles in lipid homeostasis. J Lipid Res 43: 2-12, 2002.

55. Bodzioch M, Orsó E, Klucken J, Langmann T, Böttcher A, Diederich W, Drobnik W, Barlage S, Büchler C, Porsch-Ozcürümez $\mathrm{M}$, et al: The gene encoding ATP-binding cassette transporter 1 is mutated in Tangier disease. Nat Genet 22: 347-351, 1999.

56. Bossi P, Bergamini C, Siano M, Cossu Rocca M, Sponghini AP, Favales F, Giannoccaro M, Marchesi E, Cortelazzi B, Perrone F, et al: Functional genomics uncover the biology behind the responsiveness of head and neck squamous cell cancer patients to cetuximab. Clin Cancer Res 22: 3961-3970, 2016.

57. D'Amato G, Luxán G, del Monte-Nieto G, Martínez-Poveda B, Torroja C, Walter W, Bochter MS, Benedito R, Cole S, Martinez F, et al: Sequential Notch activation regulates ventricular chamber development. Nat Cell Biol 18: 7-20, 2016.

58. Boerwinkle E, Menzel HJ, Kraft HG and Utermann G: Genetics of the quantitative Lp(a) lipoprotein trait. III. Contribution of $\mathrm{Lp}$ (a) glycoprotein phenotypes to normal lipid variation. Hum Genet 82: 73-78, 1989.

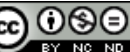

This work is licensed under a Creative Commons Attribution-NonCommercial-NoDerivatives 4.0 International (CC BY-NC-ND 4.0) License. 